\title{
The Macroeconomic Risks of Undesirably Low Inflation
}

Arias, Jonas E., Christopher Erceg and Mathias Trabandt

Please cite paper as:

Arias, Jonas E., Christopher Erceg and Mathias Trabandt

(2016). The Macroeconomic Risks of Undesirably Low Inflation International Finance Discussion Papers 1162.

http://dx.doi.org/10.17016/IFDP.2016.1162

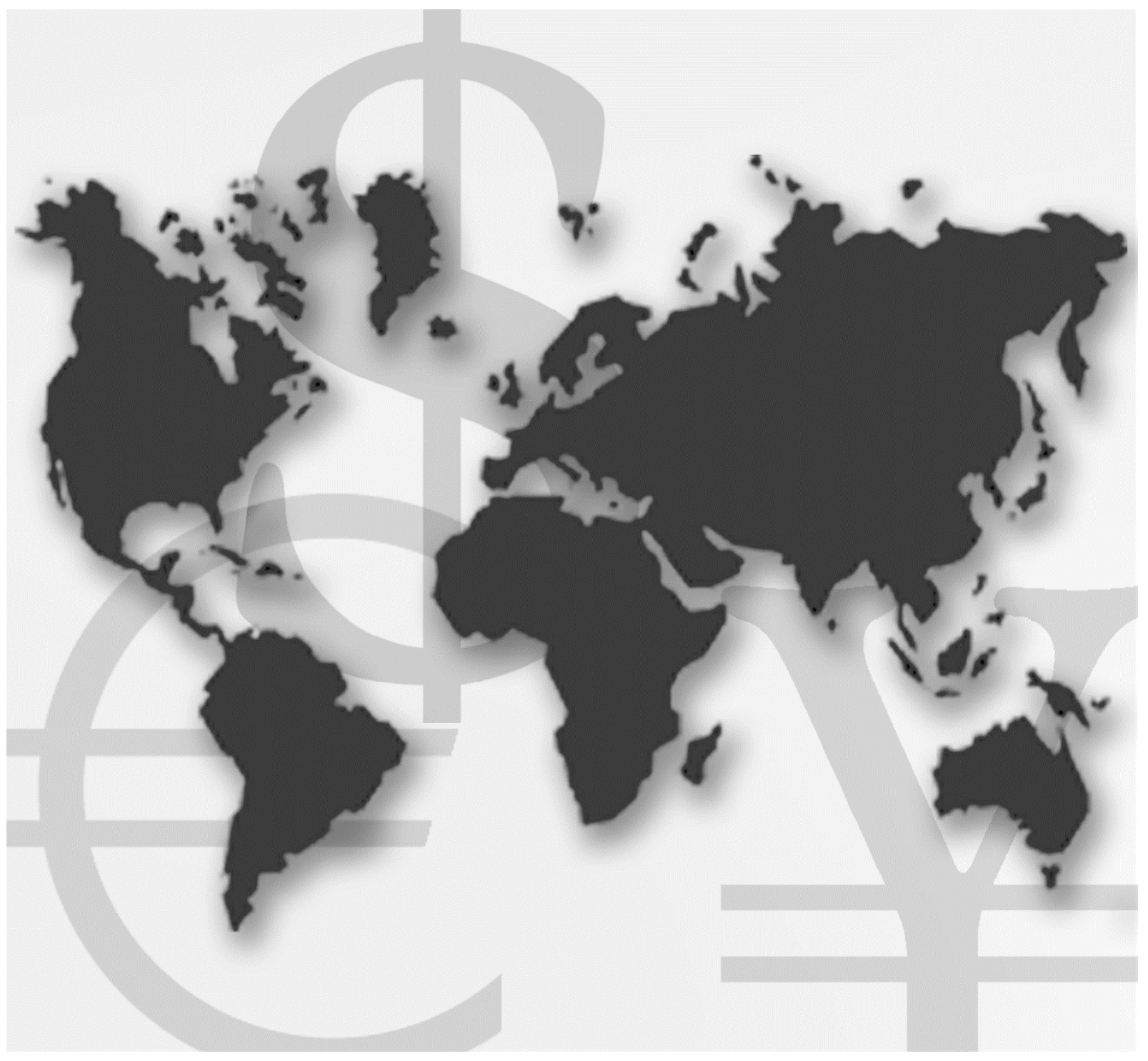

\section{International Finance Discussion Papers}

Board of Governors of the Federal Reserve System

Number 1162

April 2016 


\title{
Board of Governors of the Federal Reserve System International Finance Discussion Papers \\ Number 1162
}

April 2016

\section{The Macroeconomic Risks of Undesirably Low Inflation}

\author{
Jonas E. Arias, Christopher Erceg, and Mathias Trabandt
}

NOTE: International Finance Discussion Papers are preliminary materials circulated to stimulate discussion and critical comment. References to International Finance Discussion Papers (other than an acknowledgment that the writer has had access to unpublished material) should be cleared with the author or authors. Recent IFDPs are available on the Web at www.federalreserve.gov/pubs/ifdp/. This paper can be downloaded without charge from Social Science Research Network electronic library at www.ssrn.com. 


\title{
The Macroeconomic Risks of Undesirably Low Inflation*
}

\author{
Jonas E. Arias ${ }^{\dagger}$ \\ Federal Reserve Board \\ Christopher Erceg $\ddagger$ \\ Federal Reserve Board \\ Mathias Trabandt $\$$ \\ Freie Universität Berlin
}

April 12, 2016

\begin{abstract}
This paper investigates the macroeconomic risks associated with undesirably low inflation using a medium-sized New Keynesian model. We consider different causes of persistently low inflation, including a downward shift in long-run inflation expectations, a fall in nominal wage growth, and a favorable supply-side shock. We show that the macroeconomic effects of persistently low inflation depend crucially on its underlying cause, as well as on the extent to which monetary policy is constrained by the zero lower bound. Finally, we discuss policy options to mitigate these effects.
\end{abstract}

JEL Classification: E52, E58

Keywords: Inflation Expectations, Wages, Productivity, Disinflation, Monetary Policy, Liquidity Trap, DSGE Model.

${ }^{*}$ The views expressed in this paper are solely the responsibility of the authors and should not be interpreted as reflecting the views of the Board of Governors of the Federal Reserve System or of any other person associated with the Federal Reserve System. We thank Günter Coenen, Jesús Fernandez-Villaverde, Cosmin Illut, Robert Kollmann, Eric Leeper, Jesper Linde, Bartosz Mackowiak, and Werner Röger for helpful comments and suggestions. We also thank participants at the Post-Crisis Slump conference hosted by the European Commission and at the Workshop on Methods and Applications for DSGE Models hosted by the Federal Reserve Bank of Philadelphia.

${ }^{\dagger}$ Board of Governors of the Federal Reserve System, Division of International Finance, Global Modeling Studies Section, 20th Street and Constitution Avenue N.W., Washington, D.C. 20551, USA, E-mail: jonas.e.arias@frb.gov.

${ }^{\ddagger}$ Board of Governors of the Federal Reserve System, Division of International Finance, 20th Street and Constitution Avenue N.W., Washington, D.C. 20551, USA, E-mail: christopher.erceg@frb.gov.

${ }^{\S}$ Freie Universität Berlin, School of Business and Economics, Chair of Macroeconomics, Boltzmannstraße 20, 14195 Berlin, Germany, E-mail: mathias.trabandt@gmail.com. 


\section{Introduction}

In the wake of substantial declines in inflation during the past two years, there is growing concern that inflation may remain undesirably low in many advanced economies and even in some emerging markets. Policymakers have been especially focused on sizeable declines in market-based measures of longer-run inflation expectations. A fall in long-run inflation expectations could cause the low inflation experienced in recent years to become more deeply rooted, just as the upward drift in inflation expectations during the 1970s helped fuel a long period of undesirably high inflation. Measures of long-term inflation compensation in both the euro area and Japan hovered around 1 percent in late 2015, well below the inflation targets of their respective central banks.

Policymakers have emphasized how persistently low inflation poses substantial macroeconomic risks if monetary policy is constrained by the zero bound, and could derail economic recovery. In this vein, ECB Vice President Vítor Constâncio observed that:

"If a low inflation outlook became entrenched in the expectations of firms and households, the real interest rate would rise, leading consumers and investors to postpone their expenditure plans. A vicious circle of lower demand and lower prices could ensue." Constâncio (2014)

Moreover, even if the zero lower bound is not presently binding, persistently low inflation tends to depress the average level of policy rates, leaving less scope for the central bank to cut interest rates in the event of adverse shocks. These concerns about potentially toxic interactions between a decline in inflation expectations and the zero bound are in stark contrast to the once prevalent view - prior to Japan's struggle with deflation beginning in 
the 1990 s - that a decline in long-run inflation expectations is likely to have minimal or even benign effects on output.

In this paper, we use a medium-scale model similar to Christiano, Eichenbaum and Evans (2005) (henceforth CEE) to analyze both the macroeconomic causes and consequences of a prolonged period of low inflation, with a particular focus on how the effects depend on the zero lower bound on policy rates. Broadly speaking, we show that the costs of persistently low inflation depend heavily on the underlying cause(s), and hence it is crucial to differentiate between various sources of disinflationary (or deflationary) pressure. If the disinflationary pressure is driven purely by shifts in nominal variables, or by changes in the speed of wage or price adjustment - and hence is not associated with changes in the longer-run supply potential of the economy - it has contractionary effects on output in a liquidity trap. By contrast, if low inflation is driven by a persistent rise in productivity, then it is quite likely to cause output to expand.

Specifically, we begin by considering a fall in long-run inflation expectations below the central bank's inflation target. Such a development would have minimal effects on output if the central bank was free to adjust policy rates, or at least could do so in the fairly nearterm. By contrast, a fall in long-run inflation expectations reduces output substantially if the economy is mired in a persistent liquidity trap. This reflects that the fall in long-run inflation expectations boosts real interest rates far out the yield curve, including through extending the duration of the liquidity trap (which is determined endogenously in our model). Near-term inflation declines even more than long-term inflation due to the widening output gap, with lower inflation amplifying the gap in line with the "vicious circle" described by ECB Vice President Vítor Constâncio. 
While suggestive, this analysis understates the economic costs of a fall in inflation expectations by abstracting from any additional shocks: in reality, the economy would be more vulnerable to adverse shocks. We use stochastic simulations of our model - with the shocks calibrated to imply empirically-reasonable variations in output and inflation - to show how the probability distribution of output becomes sharply skewed to the left by the interaction of lower inflation expectations and adverse shocks. Thus, lower long-term inflation expectations not only depress the mean level of output in a liquidity trap but also intensify downside risks.

Even if long-run inflation expectations were to remain tethered to the inflation target, changes in the transmission of price and wage inflation - as captured by the price and wage Phillips Curves - are a second potentially important source of disinflation pressure. The sharp wage declines across euro area periphery economies in recent years suggests reduced worker bargaining power in the face of chronically high unemployment. Greater wage flexibility is likely to be desirable in normal times, as it tends to improve competitiveness and reduce possible tensions between stabilizing output and inflation (Blanchard and Galí (2007)). The merits of greater wage flexibility in a liquidity trap are less clear, and have been debated since the Great Depression: Viner (1933), for instance, argued that faster wage cuts would help stimulate a rebound in employment. By contrast, we show that a deceleration in nominal wage growth due to higher wage flexibility can have sharply contractionary effects on output in a liquidity trap by causing price inflation to fall and real interest rates to rise.

We then proceed to consider the effects of productivity shocks in a liquidity trap. While a favorable TFP shock boosts wealth in the longer-term (assuming it is sufficiently persistent), it reduces inflation in the near-term, and hence boosts real interest rates. As emphasized 
by Eggertsson (2010) and Wieland (2015), the latter effect dominates in standard New Keynesian models if the productivity shock dissipates before the liquidity trap ends. However, productivity changes often have a highly persistent or even permanent character - including the fall in productivity experienced by many economies following the global financial crisis - and it is less clear how such productivity changes are likely to affect output, especially in the near-term. While Christiano, Eichenbaum and Trabandt (2015) showed that the persistent slowdown in U.S. productivity growth was an important drag on U.S. output during the Great Recession, Eggertsson, Ferrero and Raffo (2014) found that permanent aggregate supply shocks have short-run effects on output of the opposite sign.$^{1}$

We use a simplified variant of the medium-scaled model - essentially, the canonical New Keynesian model with external habit persistence - to illustrate the key factors affecting the response of output to a permanent (positive) productivity shock in a liquidity trap. The inclusion of habit is useful to highlight how structural factors that affect the response of desired savings can play a critical role in determining the output response. We show that if inflation is very responsive to output, even permanent productivity shocks may cause output to contract for some time (especially if the ZLB is long-lived). Nevertheless, we argue that models which feature an empirically plausible responsiveness of inflation to resource slack imply that positive productivity shocks are likely to boost output even in the short-run. We illustrate this result both in the simple model with habit and the medium-scale model. Thus, some disinflationary pressure may be "good" or "benign" insofar as it is driven by shocks likely to boost output both in the near-term, and at longer-horizons.

We conclude with a brief discussion of how monetary policy can help to alleviate low

\footnotetext{
${ }^{1}$ Specifically, Eggertsson, Ferrero and Raffo 2014 ) considered the effects of a permanent fall in markups.
} 
inflation pressures. An important and influential literature has recommended commitmentbased strategies such as price level targeting, including e.g., Eggertsson and Woodford (2003). While potentially efficacious, such an approach would involve a substantial departure from the typical focus of central banks on inflation. We suggest an alternative in which monetary policy responds to a broad measure of resource slack that includes a state variable - the capital gap in our model, or the labor force participation gap in a model with richer labor market features - that recovers particularly slowly following an economic downturn (see e.g. Erceg and Levin (2014)). Because such a rule causes inflation and output to overshoot as the economy recovers, it boosts longer-term inflation expectations while the economy is still mired in recession, which mitigates the severity of the fall in both inflation and output.

The paper is organized as follows. Section two describes the medium-scale model. Section three examines the macroeconomic effects and consequences of persistently low inflation. Finally, section four concludes.

\section{A Medium-Sized New Keynesian Model}

Our model is a slightly simplified variant of the CEE model. As such, it incorporates nominal rigidities by assuming that labor and product markets exhibit monopolistic competition, and that wages and prices are determined by staggered nominal contracts of random duration following Calvo (1983) and Yun (1996). In addition, the model features an array of real rigidities, including habit persistence in consumption and costs of changing investment. Monetary policy follows a Taylor rule subject to the zero lower bound (ZLB) constraint on the nominal policy rate. 


\subsection{Firms}

Final-Good Firms. We assume that a single final output good $Y_{t}$ is produced using a continuum of differentiated intermediate goods $Y_{t}(f)$ for $f \in[0,1]$. The technology for transforming these intermediate goods into the final output good is constant returns to scale, and is of the Dixit-Stiglitz form:

$$
Y_{t}=\left[\int_{0}^{1} Y_{t}(f)^{\frac{1}{1+\theta_{p}}} d f\right]^{1+\theta_{p}}
$$

where $\theta_{p}>0$. Final-good firms operate in a perfectly competitive market. Thus, final-good producers minimize the cost of producing a given quantity of output $Y_{t}$, taking as given the price $P_{t}(f)$ of each intermediate good $Y_{t}(f)$. Moreover, final-good producers sell units of the final output good at a price $P_{t}$ that can be interpreted as the aggregate price index:

$$
P_{t}=\left[\int_{0}^{1} P_{t}(f)^{-\frac{1}{\theta_{p}}} d f\right]^{-\theta_{p}} .
$$

Intermediate-Goods Firms. A continuum of intermediate goods $Y_{t}(f)$ is produced by monopolistically competitive firms, each of which produces a single differentiated good. Each intermediate-goods producer faces a demand function for its output good that varies inversely with its output price $P_{t}(f)$, and directly with aggregate demand $Y_{t}$ :

$$
Y_{t}(f)=\left[\frac{P_{t}}{P_{t}(f)}\right]^{\frac{1+\theta_{p}}{\theta_{p}}} Y_{t} .
$$

Each intermediate-goods producer utilizes capital services $K_{t}(f)$ and a labor index $L_{t}(f)$ 
to produce its respective output good. The form of the production function is Cobb-Douglas:

$$
Y_{t}(f)=a_{t} K_{t}(f)^{\alpha}\left(z_{t} L_{t}(f)\right)^{1-\alpha}-\phi \Phi_{t}
$$

where $\phi$ represents a fixed cost of production. $\Phi_{t}$ is an exogenous process that ensures balanced growth as described in section 2.4. Firms face perfectly competitive factor markets for hiring capital and the labor index. Thus, each firm chooses $K_{t}(f)$ and $L_{t}(f)$, taking as given the cost of these factors of production as well as the level of the stationary and unitroot technology processes $a_{t}$ and $z_{t}$, respectively. Moreover, firms can costlessly adjust either factor of production. Thus, the standard static first-order conditions for cost minimization imply that all firms have identical marginal cost per unit of output.

The prices of the intermediate goods are determined by Calvo style staggered nominal contracts. In each period, each firm $f$ faces a constant probability, $1-\xi_{p}$, of being able to reoptimize its price $P_{t}(f)$. The probability that any firm receives a signal to reset its price is assumed to be independent of the time at which it last reset its price $2^{2}$

\subsection{Households}

We assume a continuum of monopolistically competitive households, each of which supplies a differentiated labor service to the production sector; that is, goods-producing firms regard each household's labor services $N_{t}(h), h \in[0,1]$, as an imperfect substitute for the labor services of other households. It is convenient to assume that a representative labor aggregator combines households' labor hours in the same proportions as firms would combine them.

\footnotetext{
${ }^{2}$ If a firm is not allowed to optimize its price in a given period, we assume that it adjusts its price according to $P_{t}(f)=\pi_{t-1}^{\iota_{p}} \pi^{1-\iota_{p}} P_{t-1}(f)$ where $\pi$ denotes the gross inflation rate and $0 \leq \iota_{p} \leq 1$.
} 
Thus, the aggregator's demand for each household's labor is equal to the sum of firms' demands. The labor index $L_{t}$ has the Dixit-Stiglitz form:

$$
L_{t}=\left[\int_{0}^{1} N_{t}(h)^{\frac{1}{1+\theta_{w}}} d h\right]^{1+\theta_{w}},
$$

where $\theta_{w}>0$. The aggregator minimizes the cost of producing a given amount of the aggregate labor index, taking each household's wage rate $W_{t}(h)$ as given, and then sells units of the labor index to the production sector at their unit cost $W_{t}$ :

$$
W_{t}=\left[\int_{0}^{1} W_{t}(h)^{-\frac{1}{\theta_{w}}} d h\right]^{-\theta_{w}} .
$$

It is natural to interpret $W_{t}$ as the aggregate wage index. The aggregator's demand for the labor hours of household $h$ - or equivalently, the total demand for this household's labor by all goods-producing firms - is given by:

$$
N_{t}(h)=\left[\frac{W_{t}}{W_{t}(h)}\right]^{\frac{1+\theta_{w}}{\theta_{w}}} L_{t} .
$$

The utility functional of a typical member of household $h$ is:

$$
\mathbb{E}_{t} \sum_{j=0}^{\infty} \beta^{j}\left[\nu_{t+j} \ln \left(C_{t+j}(h)-b C_{t+j-1}\right)-\frac{\chi_{0}}{1+\chi} N_{t+j}(h)^{1+\chi}\right],
$$

where the discount factor $\beta$ satisfies $0<\beta<1$. The period utility function depends on household $h$ 's current consumption $C_{t}(h)$, as well as on lagged aggregate per capita consumption to allow for the possibility of external habit persistence as in Smets and Wouters 
(2007). A positive consumption preference shock $\nu_{t}$ raises the marginal utility of consumption associated with any given consumption level. The period utility function also depends inversely on hours worked $N_{t}(h)$.

Household $h$ 's budget constraint in period $t$ states that its expenditure on goods and net purchases of financial assets must equal its disposable income:

$$
\begin{aligned}
& P_{t} C_{t}(h)+P_{I, t} I_{t}(h)+\int_{s} \xi_{t, t+1} B_{D, t+1}(h)-B_{D, t}(h) \\
= & W_{t}(h) N_{t}(h)+R_{K, t} K_{t-1}(h)+\Gamma_{t}(h)-T_{t}(h) .
\end{aligned}
$$

The household purchases the consumption good from the final-good producers, and the investment good $I_{t}(h)$ from investment-good firms operating in a perfectly competitive market using a linear technology in which one unit of the final output good is transformed into $\Psi_{t}$ units of $I_{t}(h)-$ where $\Psi_{t}$ is an exogenous unit-root process. Thus, the nominal price of the investment good $P_{I, t}$ equals the corresponding marginal cost $P_{t} / \Psi_{t}$. Investment in physical capital augments the household's (end-of-period) capital stock $K_{t}(h)$ according to:

$$
K_{t}(h)=(1-\delta) K_{t-1}(h)+\zeta_{I, t}\left[1-S\left(I_{t}(h) / I_{t-1}\right)\right] I_{t}(h)
$$

where $\zeta_{I, t}$ is a stationary investment technology shock, and $S(\cdot)$ is a convex cost of adjusting investment. The functional form of $S(\cdot)$ is discussed in section 2.4. Note that we assume that households take aggregate investment $I_{t-1}$ as given when choosing $I_{t}(h)$.

In addition to accumulating physical capital, we assume that households can engage in frictionless trading of a complete set of state-contingent bonds. The term $\int_{s} \xi_{t, t+1} B_{D, t+1}(h)-$ $B_{D, t}(h)$ represents net purchases of state-contingent bonds, with $\xi_{t, t+1}$ denoting the state 
price, and $B_{D, t+1}(h)$ the quantity of such claims purchased at time $t$. Each member of household $h$ earns labor income $W_{t}(h) N_{t}(h)$ and capital rental income $R_{K, t} K_{t-1}(h)$. Each member also receives an aliquot share $\Gamma_{t}(h)$ of the profits of all firms, and pays a lump-sum tax of $T_{t}(h)$ (this may be regarded as taxes net of any transfers).

In every period $t$, each household maximizes the utility functional (8) with respect to its consumption, investment, (end-of-period) capital stock, bond holdings, and holdings of contingent claims, subject to its labor demand function (7), budget constraint (9), and transition equation for capital (10). As in Erceg, Henderson and Levin (2000), households also set nominal wages in Calvo-style staggered contracts that are generally similar to the price contracts described above. Thus, the probability that a household receives a signal to reoptimize its wage contract in a given period is denoted by $1-\xi_{w} !^{3}$

\subsection{Monetary Policy}

We now characterize how monetary policy operates in our model taking into account the nonnegativity constraint on the nominal interest rate. Let $Z_{t}$ denote a gross 'shadow' nominal rate of interest, which satisfies the following Taylor-style monetary policy rule:

$$
\ln \left(Z_{t} / Z\right)=\gamma_{z} \ln \left(Z_{t-1} / Z\right)+\left(1-\gamma_{z}\right)\left[\ln \left(\pi_{t} / \pi^{*}\right)+\gamma_{\pi} \ln \left(\pi_{t} / \pi_{t}^{*}\right)+\gamma_{x} \ln \left(L_{t} / L_{t}^{p o t}\right)\right]
$$

where $\pi_{t}^{*}$ is the central bank's inflation target, which is assumed to follow an exogenous process. The variable $L_{t}^{\text {pot }}$ denotes the potential level of hours worked (or employment), meaning the level of hours that would prevail in the absence of any price or wage rigidities.

\footnotetext{
${ }^{3}$ If a household is not allowed to reoptimize its wage in a given period, we assume it sets its wage according to $W_{t}(h)=\pi_{t-1}^{\iota_{w}} \pi^{1-\iota_{w}} \mu W_{t-1}(h)$, where $\mu$ denotes the unconditional growth rate of output.
} 
Thus, monetary policy can be regarded as responding to the employment gap. The actual (gross nominal) policy rate, $R_{t}$, is determined as follows:

$$
\ln R_{t}=\max \left\{0, \ln Z_{t}\right\}
$$

\subsection{Market Clearing, Balanced Growth and Functional Forms}

In our model total output (or GDP) is subject to the resource constraint:

$$
Y_{t}=C_{t}+I_{t} / \Psi_{t}+\Phi_{t} g
$$

where $g$ denotes exogenous government spending (which is itself assumed to be financed by lump-sum taxes).

In addition, market clearing in capital and labor markets requires

$$
\begin{aligned}
L_{t} & =\int N_{t}(h) d h=\int N_{t}(f) d f \\
K_{t-1} & =\int K_{t-1}(h) d h=\int K_{t}(f) d f .
\end{aligned}
$$

The sources of growth in our model are the unit-root process for labor-augmenting technology $z_{t}$ and the unit-root process for investment-specific technology $\Psi_{t}$. We assume that $\ln \left(z_{t} / z_{t-1}\right) \equiv \ln \mu_{z, t}$ follows an exogenous stationary process. Further we assume investmentspecific technology to grow at a constant rate, i.e. $\ln \left(\Psi_{t} / \Psi_{t-1}\right) \equiv \ln \mu_{\Psi}$. The composite level

of technology along a balanced growth path in our model is $\Phi_{t}=\Psi_{t}^{\frac{\alpha}{1-\alpha}} z_{t}$. The unconditional growth rate of $\Phi_{t}$ is denoted by $\mu$. 
The functional form of the investment adjustment cost function, $S(\cdot)$, is:

$$
S\left(\frac{I_{t}(h)}{I_{t-1}}\right)=\frac{1}{2}\left(\exp \left[\sqrt{\psi_{I}}\left(\frac{I_{t}(h)}{I_{t-1}}-\mu \times \mu_{\Psi}\right)\right]+\exp \left[-\sqrt{\psi_{I}}\left(\frac{I_{t}(h)}{I_{t-1}}-\mu \times \mu_{\Psi}\right)\right]\right)-1
$$

The value of $I_{t}(h) / I_{t-1}$ in the nonstochastic steady state is $\left(\mu \times \mu_{\Psi}\right)$. In addition, the parameter $\psi_{I}$ denotes the second derivative of $S(\cdot)$, evaluated at the nonstochastic steady state.

\subsection{Exogenous Stochastic Processes}

We complete the characterization of our model by describing the exogenous stochastic processes that are used in the construction of the baseline, the scenarios, and the stochastic simulation below. These processes are the exogenous stochastic processes for the consumption preference shifter $\nu_{t}$, the inflation target, $\pi_{t}^{*}$, the level of neutral technology, $a_{t}$, the level of investment technology, $\zeta_{I, t}$, the growth rate of labor-augmenting technology, $\mu_{z, t}$, and an exogenous component of the return on capital, $\Delta_{t}$. We have previously defined these variables except for $\Delta_{t}$, which we assume to enter into the FOC for capital accumulation akin to the financial wedge discussed in Christiano, Eichenbaum and Trabandt (2015). Section 3 contains more details about $\Delta_{t}$. We will discuss how shocks to these exogenous variables

play a role in the construction of the baseline and the scenarios. At this stage, it suffices to assume that the consumption preference shifter and the exogenous component of the return on capital follow the $\mathrm{AR}(1)$ processes:

$$
\ln \nu_{t}=\left(1-\rho_{\nu}\right) \ln \nu+\rho_{\nu} \ln \nu_{t-1}+\sigma_{\nu} \varepsilon_{t}^{\nu}, \quad \varepsilon_{t}^{\nu} \sim \mathcal{N}(0,1)
$$


and

$$
\ln \Delta_{t}=\left(1-\rho_{\Delta}\right) \ln \Delta+\rho_{\Delta} \ln \Delta_{t-1}+\sigma_{\Delta} \varepsilon_{t}^{\Delta}, \quad \varepsilon_{t}^{\Delta} \sim \mathcal{N}(0,1)
$$

The inflation target evolves according to the following ARMA process:

$$
\ln \pi_{t}^{*}=\left(1-\rho_{\pi}\right) \ln \pi^{*}+\rho_{\pi} \ln \pi_{t-1}^{*}+\sigma_{\pi} \varepsilon_{t}^{\pi}+\sigma_{H \pi} e_{t-H}^{\pi}, \quad \varepsilon_{t}^{\pi}, e_{t-H}^{\pi} \sim \mathcal{N}(0,1) .
$$

Note that while $\varepsilon_{t}^{\pi}$ allows for contemporaneous shocks to the inflation target, the term $e_{t-H}^{\pi}$ is included to allow for the possibility of anticipated shocks (sometimes called news shocks) to the inflation target that materialize with a delay of $\mathrm{H}$ periods.

Stationary neutral technology $a_{t}$ enters into the production function of intermediate good producers as shown in equation (4), and evolves according to

$$
\ln a_{t}=\left(1-\rho_{a}\right) \ln \bar{a}+\rho_{a} \ln a_{t-1}+\sigma_{a} \varepsilon_{t}^{a}, \quad \varepsilon_{t}^{a} \sim \mathcal{N}(0,1) .
$$

Stationary investment technology $\zeta_{I, t}$ enters into the law of motion for capital accumulation described by equation (10), and evolves according to

$$
\ln \zeta_{I, t}=\left(1-\rho_{\zeta_{I}}\right) \ln \bar{\zeta}_{I}+\rho_{\zeta_{I}} \ln \zeta_{t-1}+\sigma_{\zeta_{I}} \varepsilon_{t}^{\zeta_{I}}, \quad \varepsilon_{t}^{\zeta_{I}} \sim \mathcal{N}(0,1)
$$

Finally, the growth rate of labor-augmenting technology $\ln \mu_{z, t}$ follows the $\mathrm{AR}(1)$ process:

$$
\ln \mu_{z, t}=\left(1-\rho_{\mu_{z}}\right) \ln \bar{\mu}_{z}+\rho_{\zeta} \ln \mu_{z, t-1}+\sigma_{\mu_{z}} \varepsilon_{t}^{\mu_{z}}, \quad \varepsilon_{t}^{\mu_{z}} \sim \mathcal{N}(0,1)
$$




\subsection{Calibration}

We set the central bank's steady inflation target $\pi^{*}$ equal to 0.005 , an annualized inflation rate of 2 percent. We set the steady state of the growth rates of labor-augmenting technology and investment-specific technology, $\mu_{z}$ and $\mu_{\Psi}$, such that - along a balanced growth path - real GDP and investment grow at an annual rate of 1.5 and 2.5 percent, respectively. Moreover, we set the parameters characterizing the law of motion of $\mu_{z, t}$, namely $\rho_{\mu_{z}}$ and $\sigma_{\mu_{z}}$, equal to 0.2 and 1 , respectively. The discount factor $\beta$ is set to imply an annualized real interest rate of 1.5 percent. Together, the inflation target, the discount factor and balanced growth imply that the annualized quarterly nominal interest rate is 3.5 percent in steady state. The parameter determining the degree of habit persistence in consumption $b$ is set equal to 0.7 in line with the empirical estimate of Smets and Wouters (2007). The Frisch elasticity of labor supply $1 / \chi$ is set to 0.5 which is well within the range of most estimates from the empirical labor supply literature, see e.g. Domeij and Floden (2006).

The capital share parameter $\alpha$ is set to 0.36 . The quarterly depreciation rate of the capital stock, $\delta$, is set equal to 0.025 , implying an annual depreciation rate of 10 percent. We set the cost of adjusting investment parameter $\psi_{I}$ equal to 6 .

Our calibration of the parameters of the Phillips Curve implies a relatively low sensitivity of inflation to marginal cost, i.e. a relatively flat Phillips Curve. In particular, we set the price contract duration parameter $\xi_{p}$ equal to 0.95 , the price indexation parameter $\iota_{p}$ equal to 0.7 , and assume a net price markup $\theta_{p}$ equal to 0.2 .4 Our choice of the contract duration parameter implies a somewhat lower sensitivity of inflation to marginal cost - around 0.003

\footnotetext{
${ }^{4}$ It bears emphasizing that we could account for the same flat Phillips Curve slope with a much shorter mean price contract duration by allowing for strategic complementarities in price-setting as in Woodford (2003).
} 
- than most of the empirical literature estimating the Phillips Curve for industrial countries, including the estimates of Smets and Wouters (2003) for the euro area.5 Even so, our calibration of the marginal cost sensitivity is noticeably higher than the 0.001 estimated for the Chicago Federal Reserve's DSGE model by Brave et al. (2012) using post-1989 data for the United States (which thus takes account of the flattening of the Phillips Curve slope documented in recent research, see e.g., Blanchard, Cerutti and Summers (2015)) 6 Moreover, our calibration with a flat Phillips Curve slope helps to account for a decline in inflation in response to a severe recession that appears of reasonable magnitude in light of developments following the global financial crisis.

Given strategic complementarities in wage-setting across households, the wage markup influences the slope of the wage Phillips curve. Our choices of a net wage markup $\theta_{W}$ equal to 0.2 and a wage contract duration parameter $\xi_{w}$ equal to 0.8 - along with an indexation parameter $\iota_{w}$ set to 0.7 - imply that wage inflation is slightly more sensitive to the wage markup than price inflation is to the price markup.

The parameters of the monetary policy rule $\gamma_{z}, \gamma_{\pi}$, and $\gamma_{x}$ are set equal to $0.75,0.5$ and 0.25 , respectively.

The central bank's inflation target evolves according to equation (19), where $\rho_{\pi}$ is set equal to 0.999 , and $\left(\sigma_{\pi}, \sigma_{H \pi}\right)$ equal to 1 . The parameters describing the law of motion of the exogenous component of the return on capital, $\rho_{\Delta}$ and $\sigma_{\Delta}$, are set equal to 0.7 and 1 , respectively. Further, we set the autocorrelation of the stationary neutral technology shock $\rho_{a}$ and the investment technology shock $\rho_{\zeta_{I}}$ equal to 0.975 , and the autocorrelation of the

\footnotetext{
${ }^{5}$ These authors estimate a contract duration parameter of 0.90 using data from 1980:Q2 to 1999:Q4.

${ }^{6}$ To facilitate comparison with the literature, the above discussion is based on a standard log-linearized version of the Phillips Curve. Note, however, that we simulate the fully non-linear model in the next section.
} 
consumption preference process $\rho_{\nu}$ to 0.9 . We discuss how we set the standard deviations of shocks to stationary neutral technology, stationary investment technology and consumption preference in section 3.1 .1 .

\section{Low Inflation Scenarios}

We will next show how the effects of persistently low inflation - arising from several alternative sources - are influenced by the zero lower bound constraint on the nominal interest rate. To do so, we begin by constructing a "severe recession" baseline shown by the solid lines in figure 1 that captures developments likely to precipitate a protracted period at the ZLB, including a persistently negative output gap and sizeable fall in inflation below its 2 percent target. The severe recession baseline is constructed using the realization of two shocks. First, a persistently negative consumption demand shock $\nu_{t}$ which directly impacts on the first-order condition for household consumption:

$$
\lambda_{t}(h)=\frac{\nu_{t}}{C_{t}(h)-b C_{t-1}}
$$

where $\lambda_{t}(h)$ denotes the multiplier on the household budget constraint.

Second, a persistently negative shock, $\Delta_{t}$, to the return on capital, $R_{t+1}^{k}$, which directly affects the first-order condition for physical capital:

$$
\lambda_{t}(h)=\Delta_{t} E_{t} \lambda_{t+1}(h) R_{t+1}^{k} / \pi_{t+1}
$$

Note that $\Delta_{t}$ is akin to the financial wedge discussed in Christiano, Eichenbaum and 
Trabandt (2015).

In terms of the timing of the shocks, we assume that at time $t=0$ the endogenous state variables of the economy are at their non-stochastic steady state. At time $t=1$, agents learn about the shocks $\nu_{t}$ and $\Delta_{t}$ and respond accordingly, though with the expectation that the economy will eventually return to the non-stochastic steady state. As in Christiano, Eichenbaum and Trabandt (2015), we assume certainty equivalence and solve the system of fully non-linear equations for 250 quarters using Dynare.

Next, conditional on the baseline shown in figure 1, we examine several scenarios that illustrate the macroeconomic causes and effects of a further persistent downdrift in inflation.

\subsection{Decline in Long-Run Inflation Expectations}

We begin by considering the macroeconomic consequences of a sizeable downward shift in long-run expected inflation. The ZLB constraint on policy rates would make any such decline in long-run expected inflation especially problematic. In normal times, the central bank could counter an incipient fall in long-run inflation expectations by sharply reducing policy rates, i.e. cutting the nominal policy rate enough to reduce real interest rates. By contrast, a fall in expected inflation would raise real interest rates while the ZLB is binding, forcing the central bank to rely on forward guidance - and possibly unconventional policies such as asset purchases - to offset the contractionary effects.

Figure 1 simulates the effects of a decline in long-run expected inflation. In our simulation, long-run inflation declines because the public comes to believe that the central bank will eventually choose to target a lower level of inflation than $\pi^{*}$. Specifically, we assume an anticipated shock to the inflation target such that households and firms believe that the 
inflation target will drop to 1 percent five years in the future. While highly stylized, this characterization is useful for capturing how an "unwanted" fall in long-run inflation expectations might play out: because the central bank's inflation target does not actually change in the near-term, the central bank attempts to counter the downward pressure on inflation by easing monetary policy to the extent that it has scope to do so.7 Because the economic effects depend critically on the degree to which monetary policy is constrained from reducing policy rates, figure 1 examines two scenarios.

In normal times - the "Decline in $\pi^{e}$ Outside ZLB" scenario shown by the dotted lines - the shift in inflation expectations occurs after the economy has largely returned to steady state. In particular, the dotted line shows a scenario in which at time $t=25$ of our simulation there is a shock to the central bank's inflation target. Upon the occurrence of the shock agents believe that the inflation target will decline to 1 percent 5 years ahead. Because the central bank has latitude to reduce interest rates in real terms, GDP actually expands slightly above the baseline path (though the Taylor rule is not aggressive enough to keep inflation from declining well below 2 percent). By contrast, the "Decline in $\pi^{e}$ During ZLB" scenario depicted by the dashed lines assumes that the same-sized decline in the long-run inflation target occurs in a deep liquidity trap - time $t=5$ in the simulation. In this case, the fall in inflation causes real interest rates to rise markedly in the near-term, and the duration of the zero lower bound is extended for about a year. All told, the fall in the perceived long-run inflation target by 1 percentage point causes inflation to fall by more than that amount in the near term, and output to decline about $1 \frac{1}{4}$ percentage point below the baseline 8

\footnotetext{
${ }^{7}$ In section 3.1 .2 , we consider an alternative scenario in which inflation expectations decline even when the central bank's inflation target remains unchanged.

${ }^{8}$ De Michelis and Iacoviello (2016) study the effectiveness of the recent policies implemented by the Bank of Japan aimed at increasing long-run inflation expectations. Their findings complement our results in that output is more responsive to exogenous shifts in inflation expectations during a liquidity trap than in normal
} 


\subsubsection{Stochastic Simulations}

The simulations described above focus solely on the effects of a shift in long-run inflation expectations; as a result, they may significantly understate the economic costs because they abstract from potentially adverse complementarities between a fall in long-run inflation expectations and other adverse shocks that may also reduce demand. In particular, given the asymmetry posed by the zero bound, a fall in inflation expectations may shift the probability distribution of output towards negative outcomes, implying substantial negative skewness.

To illustrate this, we next consider the implications of a downward-shift in the inflation target in a stochastic environment. To do so, we proceed in two steps. First, we calibrate the standard deviations of three shocks such that the model matches some key moments in the data. Second, we subject the model to realizations of these shocks when inflation expectations drift downward - comparing the effects in "normal times" with those in a liquidity trap.

Specifically, we select the standard deviations of the shocks to stationary neutral technology $\sigma_{a}$, stationary investment technology $\sigma_{\zeta_{I}}$, and consumption preference $\sigma_{\nu}$, so that the model matches exactly some key macroeconomic moments over the Great Moderation sample period of 1982Q4 to 2008Q2 that are shown in table 1. These moments are: the standard deviation of 4-quarter GDP growth, the standard deviation of 4-quarter inflation, and the correlation between these variables.$^{9}$ This yields $\sigma_{a}$ equal to $0.773, \sigma_{\zeta_{I}}$ equal to 3.996 , and $\sigma_{\nu}$ equal to 1.095

times.

${ }^{9}$ Technically, we minimize a quadratic loss function based on the squared difference between these three moments in the data and the respective model-implied moments. 


\begin{tabular}{cccc}
\hline \hline & $\sigma\left(y_{t}\right)$ & $\sigma\left(\pi_{t}\right)$ & $\operatorname{corr}\left(y_{t}, \pi_{t}\right)$ \\
\hline Data & 1.64 & 1.10 & 0.10 \\
Model & 1.64 & 1.10 & 0.10 \\
\hline \hline
\end{tabular}

Table 1: Moments of the data and model-implied moments

Using random draws from the distributions of the three shocks - which generate empiricallyreasonable variation in output and inflation - we illustrate how the probability distribution of output can be influenced by the interaction of the zero lower bound and a downward shift in long-run inflation expectations.

We begin with the case in which monetary policy is unconstrained by the ZLB - the "normal times" case shown in panel (A) of figure 2, The probability distribution of GDP shown in the panel is computed by simulating the model 5000 times around the baseline GDP path (from figure 1) using random draws of the preference shock, the neutral technology shock, and the investment technology shock. For each realization, we compute the GDP response (expressed in percent deviations from baseline) four quarters after the simulation begins. The implied (conditional) probability distribution, depicted by the solid gray line in panel (A) of figure 2, is clearly symmetric around the baseline, as would be expected given that the underlying shocks are normally distributed. The dashed line shows that the probability distribution of output remains essentially unchanged - and symmetric around the baseline - in the case in which the perceived long-run inflation target falls to 1 percent when the economy is hit by the three shocks.

Panel (B) shows the probability distribution of output derived from stochastic simulations around the severe recession baseline shown in figure 1 in which policy rates are pinned at the ZLB, and which enforces the ZLB in the stochastic simulations. ${ }^{10}$ In this environment,

\footnotetext{
${ }^{10}$ Specifically, we again simulate the model with 5000 draws of the three stochastic shocks around the "Decline in $\pi^{e}$ During ZLB" scenario of figure 1 that begins at time $t=5$.
} 
the probability distribution of output shifts sharply to the left for the case in which the perceived long-run inflation target is only 1 percent. The negative skewness in the output distribution reflects that additional adverse shocks hit against the backdrop of very weak initial conditions in which the ZLB was already expected to bind for a long time (as seen in figure 1, roughly for four years) even before the arrival of the new adverse shocks incorporated into our stochastic scenario. Given the long-lived ZLB constraint - which is in part due to the downward shift in long-run inflation expectations - these adverse shocks have very large contractionary effects on output. All in all, these stochastic results highlight how a decline in inflation expectations may pose a serious risk for an economy mired in recession, even if it might have fairly minimal adverse implications for an economy close to full employment.

\subsubsection{Adaptive Expectations}

While our scenario above is convenient for highlighting risks posed by a decline in inflation expectations when the ZLB is binding, it seems likely that longer-run inflation expectations are influenced by a range of factors beyond the central bank's inflation target, including realized inflation. Indeed, many economists have argued that the persistent failure of central banks to keep inflation at a reasonable level in the 1970s fueled an upward drift in long-run inflation expectations that in turn fed into current inflation. On the flip side, Svensson (2013) and Draghi (2014) have underscored how the long spells of below-target inflation since the global financial crisis increase the risk that long-term inflation expectations may fall well below announced inflation targets.

Accordingly, we next consider the risk that low realized inflation is the catalyst for a fall in longer-run inflation expectations, and examine potential consequences when the ZLB is 
binding 11 To implement this, we assume that agents form inflation expectations according to:

$$
\tilde{E}_{t}\left\{\ln \pi_{t+1}\right\}=\iota \frac{1}{4}\left(\sum_{\ell=1}^{4} \ln \pi_{t-\ell}\right)+(1-\iota) \mathbb{E}_{t}\left\{\ln \pi_{t+1}\right\} .
$$

This specification models expected inflation $\tilde{E}_{t}\left\{\ln \pi_{t+1}\right\}$ as a weighted average of past inflation and of a model-consistent (or rational expectations) forecast, $\mathbb{E}_{t}\left\{\ln \pi_{t+1}\right\} .^{12}$ Thus, with $\iota$ equal to 0 , the specification is consistent with fully-rational expectations; whereas a higher $\iota$ means that inflation expectations respond more to past realized inflation. An important implication is that longer-run inflation expectations are endogenous, rather than evolving exogenously as considered above.

In our scenario, we assume that the central bank's inflation target is unchanged at 2 percent, but that there is an unanticipated change in the value of $\iota$ from 0 to 0.5 at time $t=5$. The dashed lines in figure 3 show the path of key macroeconomic variables in response to this switch in agents' inflation expectations assuming that the structural shocks are identical to those generating the recession baseline in figure 1 (thus, the macro outcomes are identical until period $t=5$ when the process for inflation expectations shifts). Panel (A) shows that 5 -year inflation expectations fall by about 0.5 percentage point in response to the decline in realized inflation in this scenario. Because the nominal interest rate (panel D) is subject to the ZLB constraint, real interest rates increase in the short run, inducing the output gap to become more negative.

The implications for output under this alternative specification for inflation expectations clearly parallel those we have discussed above for the case of an exogenous shift in the

\footnotetext{
${ }^{11}$ We thank Günter Coenen for suggesting this alternative approach.

${ }^{12}$ As discussed by Clarida, Gali and Gertler (1999) a variant of this specification has been used to motivate the dependence of current inflation on lagged inflation. Hills, Nakata and Schmidt (2016) develop a model in which long-run inflation expectations decline endogenously as the probability of hitting the ZLB increases.
} 
inflation target. Thus, a fall in long-run inflation expectations can be sharply contractionary when the ZLB is binding, even if not in normal times. However, under adaptive expectation formation, inflation expectations depend much more heavily on actual inflation outcomes than if the long-run target were to shift exogenously. Therefore, the adaptive expectations formulation suggests an even more prominent role for monetary policy to help guard against the risk of a drop in inflation expectations ${ }^{13}$

\subsection{Fall in Nominal Wage Growth}

There are a number of alternative channels or shocks that could fuel persistent downward pressure on inflation even if long-run inflation expectations remained well-anchored. One risk is that nominal wages may decelerate if long periods of high unemployment eventually make wages more sensitive to economic slack. This might occur if worker bargaining power gradually erodes in the face of protracted weakness in labor market conditions, and/or if workers become less averse to cuts in nominal wages.

Empirical evidence from Japan's experience with very low inflation in the 1990s seems consistent with these possibilities. As discussed by Kuroda and Yamamoto (2005), the distribution of nominal wage changes appeared highly concentrated to the right of zero through the early years of Japan's low inflation period, presumably reflecting staunch worker resistance to nominal wage cuts; but the proportion of workers experiencing nominal wage cuts rose markedly as the period of near zero inflation and very weak output growth dragged on. More recently, during the post-crisis slump period wage growth in euro area periphery economies sharply decelerated in the face of persistently high unemployment, turning

\footnotetext{
${ }^{13}$ We illustrate this possibility in an appendix, available upon request from the authors.
} 
markedly negative in Portugal, and to a lesser degree, in Ireland and Spain - see figure 4.

Faster wage adjustment typically has benign effects in normal times when monetary policy can freely adjust policy rates, notably by easing the tension that may arise between achieving the objectives of stabilizing both inflation and the output gap following an aggregate supply shock (Blanchard and Galí (2007)). However, a faster speed of nominal wage adjustment is likely to have contractionary effects on output in the context of a long-lived liquidity trap. In particular, rapid wage-cutting by workers would put downward pressure on inflation, raising the real interest rate. Because faster wage adjustment does not materially affect the economy's longer run potential output, this real interest rate channel is the main determinant of the effects on output.

Figure 5 illustrates the consequences of faster wage adjustment when monetary policy is constrained by the zero lower bound against the same baseline as in figure 1. In particular, we consider a scenario in which nominal wages become more sensitive to economic slack due to a sudden and unforeseen shift in the wage Phillips Curve slope parameter ${ }^{14}$ Because the fall in wage growth causes inflation to decline, real interest rates rise due to the zero lower bound constraint, exerting a sizeable contractionary impact on the economy.

\subsection{Faster TFP Growth}

Shocks that raise the economy's longer-run level of potential output tend to put downward pressure on inflation. Familiar examples include a supply-induced decline in global oil prices,

\footnotetext{
${ }^{14}$ Specifically, we assume that one year after the baseline shocks hit the economy, the Calvo wage parameter drops permanently from $\theta_{w}$ to $\theta_{w}^{\prime}$. In the benchmark calibration $\theta_{w}$ is such that wages are adjusted on average once every five quarters, while $\theta_{w}^{\prime}$ implies that wages are adjusted on average about every three quarters.
} 
or a pickup in productivity growth as occurred in the United States in the late 1990s ${ }^{15}$ In our model, expansionary aggregate supply shocks cause inflation to fall because wages adjust sluggishly, so that marginal production costs would decline even if policy rates were adjusted enough to keep output at potential; of course, the downward pressure on inflation would be larger to the extent that the central bank allowed output to fall below potential.

A key question that we now consider is whether a fall in inflation driven by a productivity shock should be regarded as a benign development - in the sense that it is likely to boost output - even when the economy is in a liquidity trap. While a rise in total factor productivity increases output in normal times in which the central bank can freely adjust policy rates, an expansion in aggregate supply may cause output to contract perversely in a liquidity trap, as has been highlighted in an influential literature, e.g. Eggertsson (2010) and Eggertsson and Krugman (2012). Intuitively, a positive productivity shock raises current aggregate demand through a wealth channel, but exerts downward pressure on inflation leading to higher real interest rates in a liquidity trap. The latter effect may dominate in a liquidity trap, so that output falls. In the simple New Keynesian model, Wieland (2015) shows that output necessarily falls in response to a transient TFP rise that fully dissipates before the liquidity trap ends ${ }^{16}$

Given that the literature has devoted substantial attention to transitory shocks, we will next explore whether shocks that permanently raise the level of TFP may be contractionary

\footnotetext{
${ }^{15}$ More recently, Bank of England officials have argued that extremely weak productivity growth since 2007 contributed to boosting inflation well above the U.K's target through much of the recovery from the financial crisis.

${ }^{16}$ Wieland (2015) argues that this implication of an output contraction in response to a transient boost to aggregate supply is inconsistent with empirical evidence from Japan on the effects of both oil shocks and a major earthquake. Accordingly, he formulates a model with financing frictions that accounts for positive comovement between transient changes in aggregate supply and output even in a liquidity trap. Incorporating financial frictions into our model would be a useful extension for future work.
} 
in a liquidity trap ${ }^{17}$ This question is important for assessing whether the persistently weak TFP growth following the financial crisis has hurt output or been salutary, and also for gauging whether structural reforms aimed to boost productivity would be likely to cause output to expand. We will then draw on this analysis to make more general observations about how the output response to TFP varies with the persistence of the TFP shock. The results of both Fernández-Villaverde, Guerrón-Quintana and Rubio-Ramírez (2014) - using a two period model - and Christiano, Eichenbaum and Trabandt (2015) - using an estimated model with capital - suggest that highly persistent or permanent TFP shocks should move output in the same direction even if the ZLB binds for a long time. By contrast, Eggertsson, Ferrero and Raffo (2014) showed that permanent reductions in wage and price markups, which could be expected to have effects similar to a permanent productivity shock, can cause output to contract in the short-run 18

Broadly speaking, these disparities in results likely reflect that a number of important factors influence the transmission of a permanent TFP shock when the ZLB is binding. Output is more likely to decline "perversely" if the ZLB binds for longer, or if the Phillips Curve slope is higher, since both of these factors translate into a larger inflation decline and thereby to a higher real rate (e.g. Eggertsson (2010)). In addition, transmission depends on the perceived persistence of the rise in productivity growth (see Fernández-Villaverde, Guerrón-Quintana and Rubio-Ramírez (2014)), the nature of the monetary reaction function, and on structural factors such as habit persistence which influence how desired savings and investment respond.

\footnotetext{
${ }^{17}$ For concreteness, we focus our discussion on shocks that raise TFP, though the analysis is equally applicable to shocks that lower TFP.

${ }^{18}$ In particular, the Eggertsson, Ferrero and Raffo (2014) result does not hold just for markup shocks: we show below that permanent positive TFP shocks also cause output to fall under certain conditions.
} 
To help identify more clearly conditions under which a permanent positive productivity shock may cause output to fall rather than to rise, it is helpful to consider a simplified variant of our model that allows for habit persistence in consumption, but is otherwise identical to the workhorse New Keynesian model. Allowing for habit helps to illustrate how structural features affecting desired saving have a major influence on transmission, and provides an important bridge between the simple models often used in the literature and our medium-scale model that includes capital and various real frictions. The simple model in log-linearized form may be represented as:

$$
\begin{aligned}
x_{t} & =\frac{1}{1+b} E_{t} x_{t+1}+\frac{b}{1+b} x_{t-1}-\sigma\left(i_{t}-E_{t} \pi_{t+1}-r_{t}^{N}\right), \\
\pi_{t} & =\beta E_{t} \pi_{t+1}+\kappa_{p}\left(x_{t}+\phi\left(x_{t}-b x_{t-1}\right)\right) .
\end{aligned}
$$

Equation (26) is the IS curve modified to include external habit - governed by the parameter $b$ - implying that the output gap $x_{t}$ depends on its own lead and lag, and inversely on the difference between the real interest rate $i_{t}-E_{t} \pi_{t+1}$ and the "neutral" or "potential" real interest rate $r_{t}^{N}$, which is the real interest rate that would keep output at potential. Equation (27) is the New Keynesian Phillips Curve linking price inflation $\pi_{t}$ to expected inflation, as well as to both the output gap and its quasi-difference (the latter reflecting habit). Finally, we assume that monetary policy reacts (simply) to the inflation gap subject to the zero lower bound.

We next use the model to examine an immediate and permanent rise in the level of TFP. In the absence of habit, i.e., $b=0$, desired consumption would immediately jump to its new longer-run level without any required adjustment in interest rates (real or nominal): this 
reflects that the shock has no effect on the neutral real interest rate $r_{t}^{N}$. Hence, neither the output gap nor inflation would be affected even in a liquidity trap, and correspondingly, output would jump up immediately in line with the increase in productivity.

With habit persistence in consumption, the implications for output can differ dramatically. As shown in panel (A) of figure 6, the permanent rise in TFP causes the neutral interest rate $r_{t}^{N}$ - the dash-dotted line - to fall relative to the baseline (the solid line) 19

Intuitively, this occurs because households prefer a smooth increase in consumption to a rapid jump, and hence would prefer to save much of their extra income. With policy rates constrained by the ZLB, the fall in the neutral rate causes output to fall (further) below potential, and this effect on the output gap is amplified by a decline in inflation (as implied by equation (27)). Figure 6 shows that if the Phillips Curve slope is relatively high (labeled "High Phillips Curve Slope"), inflation may fall enough that the contractionary effect on the output gap (panel E) is large enough to dominate the rise in potential output (panel B), so that the level of output (panel F) falls in the short run. By contrast, the dashed lines show the effects under a flatter Phillips Curve slope that is more consistent with our benchmark calibration. Inflation falls less and the output gap turns much less negative, so that the productivity shock boosts output even in the near-term.

One corollary from this analysis is that even permanent positive productivity shocks could potentially pose some risks to the economy in a liquidity trap, especially if inflation falls substantially and persistently (which is more likely to occur if the Phillips Curve has a steeper slope, and/or in times of a protracted liquidity trap). Moreover, the risks are higher

\footnotetext{
${ }^{19}$ The baseline is generated through a negative consumption preference shock that depresses potential output (panel B) and consumption. The short-lived initial spike in the neutral real interest rate reflects habit persistence in consumption.
} 
if monetary policy is not sufficiently aggressive, and allows inflation to remain persistently below target even after the liquidity trap has ended.

Notwithstanding these results, a permanent productivity shock seems likely to induce output to rise, even in the near-term, in a model with an empirically reasonable Phillips Curve slope (at least provided that the liquidity trap duration is not extremely prolonged). Output only contracts in the small model if inflation drops by an implausible amount (panel C), but otherwise expands.

These results are corroborated in our benchmark model with endogenous capital. Figure 7 illustrates the effects of an immediate rise in productivity of 5 percent. While the output gap becomes more negative due to the increase in real interest rates - as in the simple model - the level of output rises as the contractionary effects from this channel are swamped by the expectation of higher permanent income. The figure also shows a productivity shock scaled to have the same long-run effects, but which is phased-in over time. Because this contour for the productivity shock implies a rise in the neutral real rate (even taking account of adjustment costs on consumption and investment), inflation actually rises rather than falls, so that the real rate falls in the near-term in a liquidity trap, and output rises by more than potential. The latter results are similar to those emphasized by Fernández-Villaverde, Guerrón-Quintana and Rubio-Ramírez (2014). Finally, as might be guessed from the positive output response to the permanent shock, even shocks that only boost the level of TFP in a highly persistent, though not permanent, way also tend to raise output, albeit by somewhat less than shown in figure 7 .

Accordingly, persistently low inflation associated with supply shocks may be regarded as "good" or "benign" for the recovery of the real economy insofar as the negative effects 
from higher real interest rates are more than counterbalanced by positive wealth effects ${ }^{20}$ But - as we show in the next subsection - we underscore that even if output responds positively, monetary policy can play an important role in mitigating the negative output gap that productivity shocks may induce, and in reducing the likelihood that the fall in inflation associated with higher productivity becomes embedded into inflation expectations.

\subsection{Targeting Broad vs. Narrow Measures of Resource Slack}

We next briefly consider how monetary policy can mitigate the risk of persistently low inflation through its choice of a reaction function for the policy rate ${ }^{21}$ The monetary policy rule that we have assumed implies a response to inflation and the employment (or hours) gap. Equivalently, the rule may be regarded as tantamount to responding to the output gap, but taking the current level of the capital stock as the appropriate measure of potential. Such a rule typically implies nearly monotonic convergence of inflation to target and of employment to potential, at least following demand shocks. This monotonic convergence is evident in our severe recession baseline that is depicted by the solid lines in figure 8 (i.e., using the same baseline as for figure 1). This implication seems consistent with central bank forecasts and communication: central banks typically convey that they will set policy rates so that inflation will converge monotonically to target (and employment too if the shock does not generate a tension between stabilizing these objectives).

However, this monotonic convergence of inflation contrasts with the prescriptions of optimal policy in the presence of a binding zero lower bound constraint. As argued by Eggertsson

\begin{tabular}{l}
\hline${ }^{20}$ Consistent with $\mid$ Fernández-Villaverde $\mid(2014)$, some features that we abstract from in our model - such \\
as an endogenous tax reaction function for setting distortionary taxes - would likely amplify these stimulative \\
effects. \\
\hline${ }^{21}$ Of course, balance sheet policies could also be utilized to raise activity and boost inflation expectations; \\
but here we confine attention to the policy rate.
\end{tabular}


and Woodford (2003), the optimal response to an adverse demand shock would be to commit to allow inflation to rise well above target as the economy recovers, reversing any past inflation "shortfalls" in order to eventually stabilize the price level. The expectation that inflation would eventually run high would in turn mitigate the fall in inflation and output in the near-term.

These history dependent strategies could potentially be effective in anchoring long-term inflation expectations in a deep recession, and in reducing the risk that a sustained period of low inflation would cause longer-term inflation expectations to decline. Even so, by focusing on price level stability, they would involve a substantial break from the usual central bank focus on stabilizing inflation and some measure of activity.

As an alternative, a recent literature has argued that - following a deep recession monetary policy may spur a faster rebound in both inflation and output/employment by targeting a broad measure of resource slack that includes slow moving state variables such as the labor force participation rate. As shown by Erceg and Levin (2014), because the unemployment rate recovers more quickly than the labor force participation rate, a policy rule that responds both to the labor force participation gap and unemployment gap keeps interest rates lower for longer than a rule responding only to the latter. This in turn pushes unemployment to fall below its natural rate, and causes inflation to exceed the central bank's target. Thus, such a policy generates a faster recovery through allowing inflation to eventually overshoot. Moreover, while the overshooting would be costly if longer-run inflation expectations were securely anchored, it could be desirable for risk management reasons if inflation expectations were not well anchored and a return to the lower bound was a material risk. 
Accordingly, we next use our model to illustrate the consequences of reacting to a broader measure of slack: in particular, we assume that monetary policy responds to the "true" output gap, defined as the difference between output and its level under fully flexible prices and wages. Equivalently, monetary policy can be regarded as putting a sizeable weight on responding to the "true" capital gap $\ln K_{t-1}-\ln K_{t-1}^{\text {pot }}$ as well as the employment gap:

$$
\ln Y_{t}-\ln Y_{t}^{p o t}=(1-\alpha)\left(\ln L_{t}-\ln L_{t}^{p o t}\right)+\alpha\left(\ln K_{t-1}-\ln K_{t-1}^{p o t}\right) .
$$

Following a deep recession, the "true" output gap measure would clearly be much more negative than the gap measure in our benchmark in which the capital gap is ignored.

Figure 8 compares the implications of the reaction function which responds to the true output gap - the dashed lines - with our benchmark that responds only to the employment gap - the solid lines ${ }^{22}$ The former reaction function is much more stimulative: because the capital stock reacts very slowly, such a policy rule in effect acts like a promise to keep real interest rates low for much longer than under employment gap targeting. As a consequence, the employment gap overshoots, and inflation rises persistently above the 2 percent target. Although the simulations in the figure assume for simplicity that long-run inflation expectations are anchored at target, the policy rule responding to the broader measure of slack would have an even larger comparative advantage in stabilizing output and inflation if inflation expectations were partly adaptive as considered above.

There is admittedly some risk that central banks could push inflation more above target than they anticipated through such a policy, and then face a difficult task in bringing it

\footnotetext{
${ }^{22}$ Specifically, we assume that one year after the baseline shocks hit the economy, the central bank announces that it will target the output gap rather than the employment gap henceforth.
} 
back down again. The influential research by Orphanides (2003) arguing that the Great Inflation was in large part attributable to overestimating slack might seem to push in the direction of measuring slack very conservatively. However, it is arguable that there is a much more tangible risk of undershooting the inflation target in the environment of the past several years, in which major central banks have almost uniformly missed their targets to the downside, and the ZLB has remained a longstanding constraint. To the extent that greater risks are perceived to lie in the direction of undershooting inflation targets - and policymakers feel reasonably confident about their ability to eventually bring inflation down should it overshoot materially - a policy reaction function which focuses on broad measures of slack may be appealing.

\section{Conclusions}

In this paper, we have investigated the macroeconomic risks posed by low inflation, and specifically, highlighted how a persistent decline in inflation can have very costly implications for output when the zero lower bound is binding.

Even so, we have argued that it is crucial to differentiate between various sources of persistently low inflation: while a persistent fall in inflation that is driven by nominal shocks - such as a decline in long-run inflation - is contractionary, a persistent fall in inflation that is driven by a persistent rise in productivity is likely to cause output to expand even in the near-term.

We have also shown that a monetary policy framework that allows inflation to overshoot by keeping real interest rates low until slowly evolving state variables such as capital have 
recovered can mitigate downward pressure on inflation.

In the medium-scale model that we have utilized, persistently low inflation is costly because it raises the real interest rate if the monetary authority is constrained by the zero lower bound. Our model abstracts from Fisherian "debt deflation" channels whereby low inflation could adversely affect borrower balance sheets and thereby tighten financial conditions for both households and firms. Similarly, undesirably low inflation in a liquidity trap affects the government's budget position, reflecting that higher interest rates tend to boost the stock of debt, and cause the primary balance to deteriorate by weakening the macroeconomic outlook. There may well be an adverse feedback loop from inflation to government debt that depends on the fiscal reaction function, e.g., rising debt may trigger sharp cuts in public spending.

Finally, our solution method excludes considerations about how uncertainty might affect saving and investment decisions, and thus how low inflation might depress real interest rates through effects on precautionary savings (see Basu and Bundick (2015)). All of the issues mentioned above seem worthwhile to pursue in future research. 


\section{$5 \quad$ Figures}

Baseline $-\quad-$ Decline in $\pi^{\mathrm{e}}$ During ZLB $\cdots \cdots \cdot$ Decline in $\pi^{\mathrm{e}}$ Outside ZLB

(A) 5-Year Ahead $\pi^{\mathrm{e}}$ (annual \%)

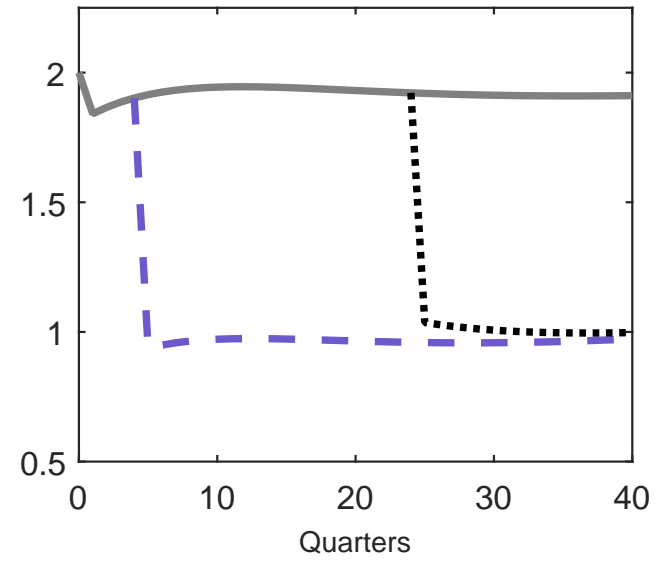

(C) Wage Inflation (annual \%)

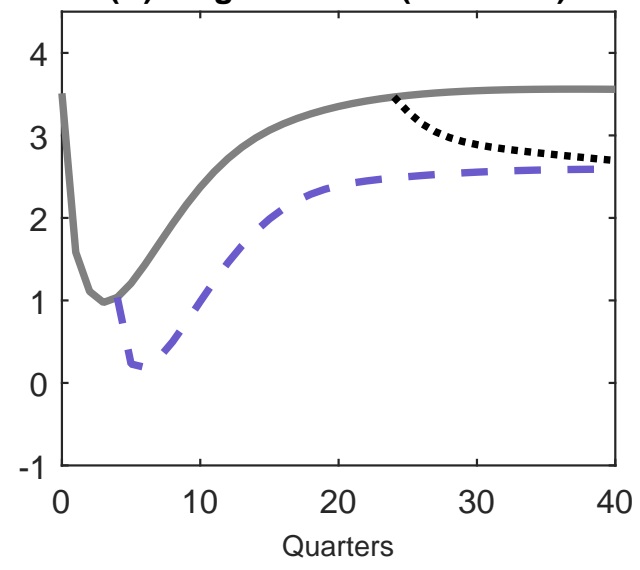

(E) Real Interest Rate (annual \%)

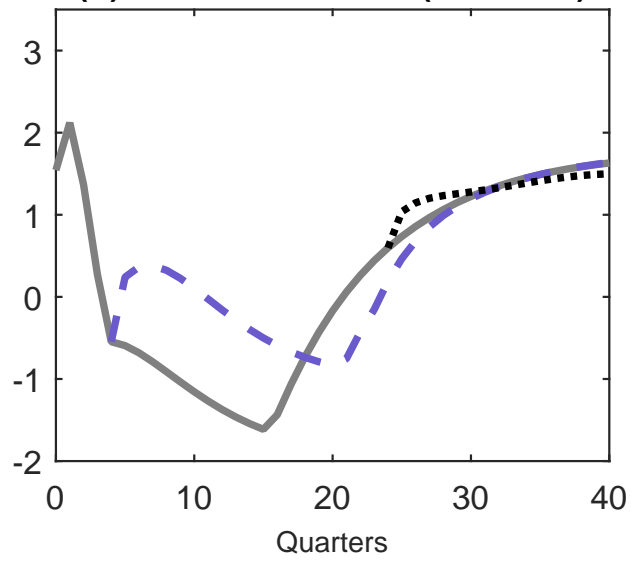

(B) Price Inflation (annual \%)

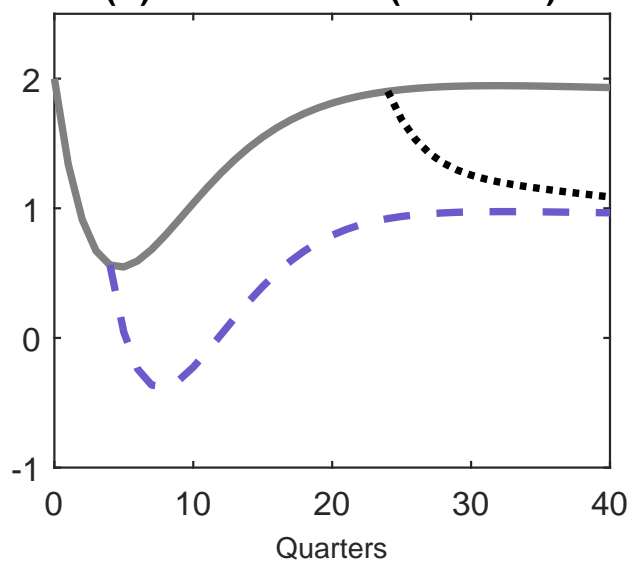

(D) Nominal Interest Rate (annual \%)

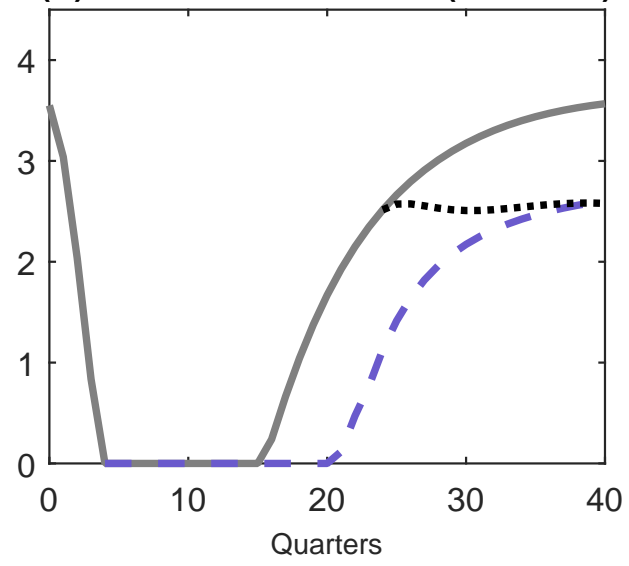

(F) Output Gap (\%)

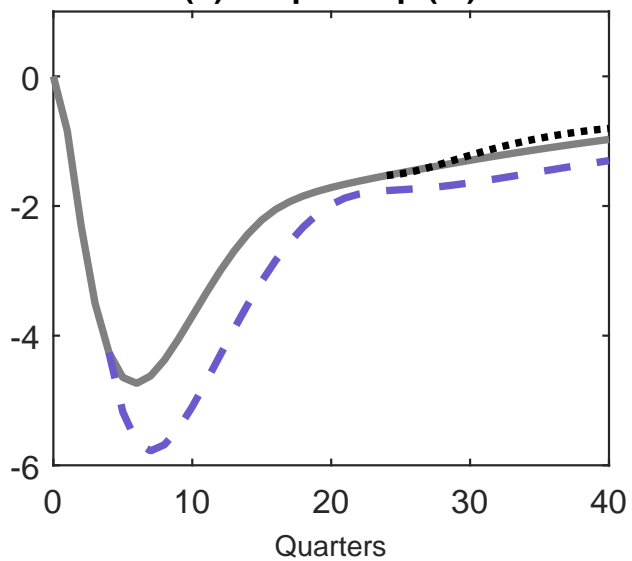

Figure 1: Effects of a decline in $\pi^{e}$. 

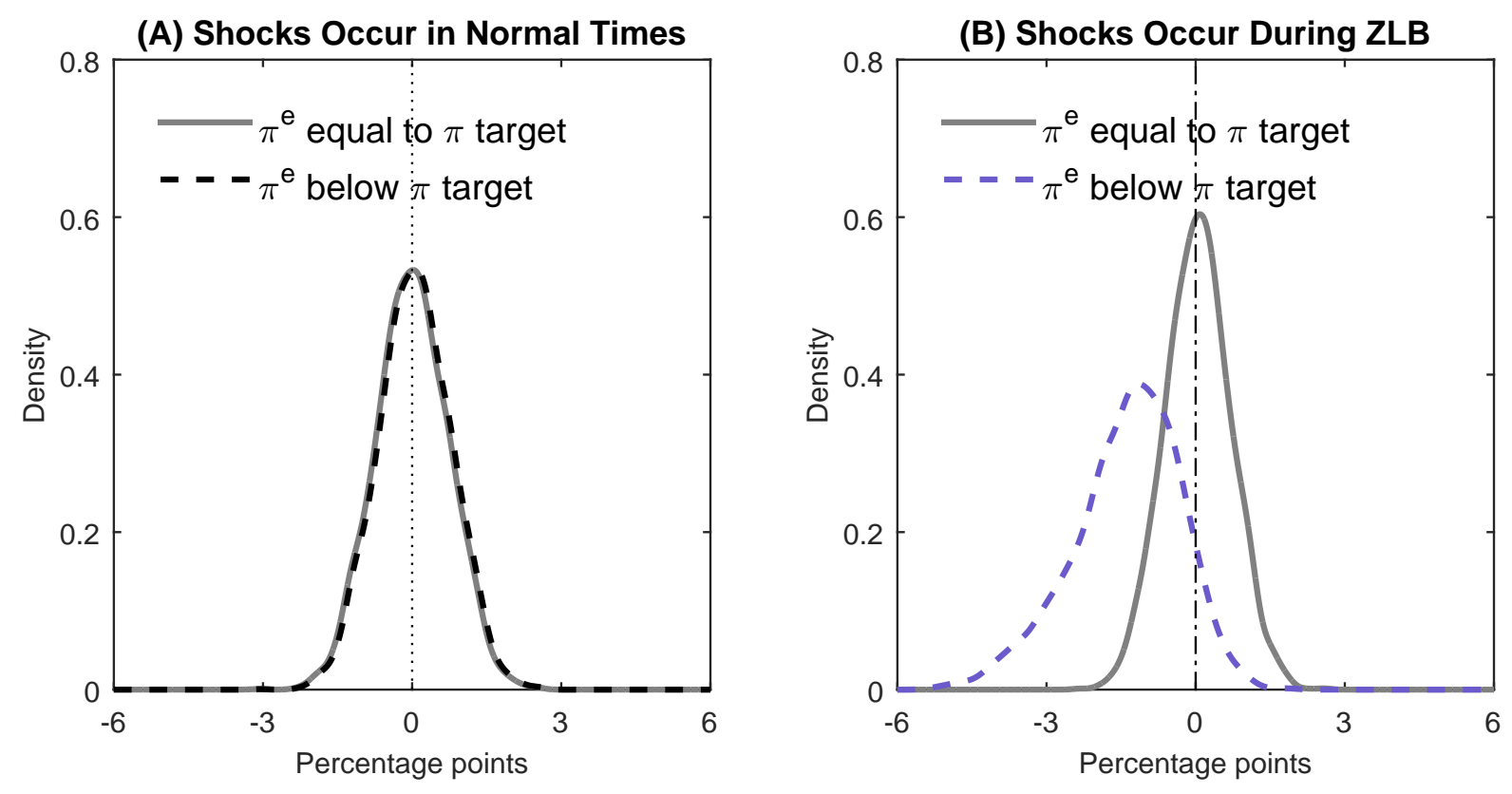

Figure 2: Stochastic simulation of the effects of demand and supply shocks on GDP. The density shown in the figure corresponds to the deviations of GDP from baseline 1 year after the shocks. 
Baseline - - Decline in $\pi^{\mathrm{e}}$ During ZLB

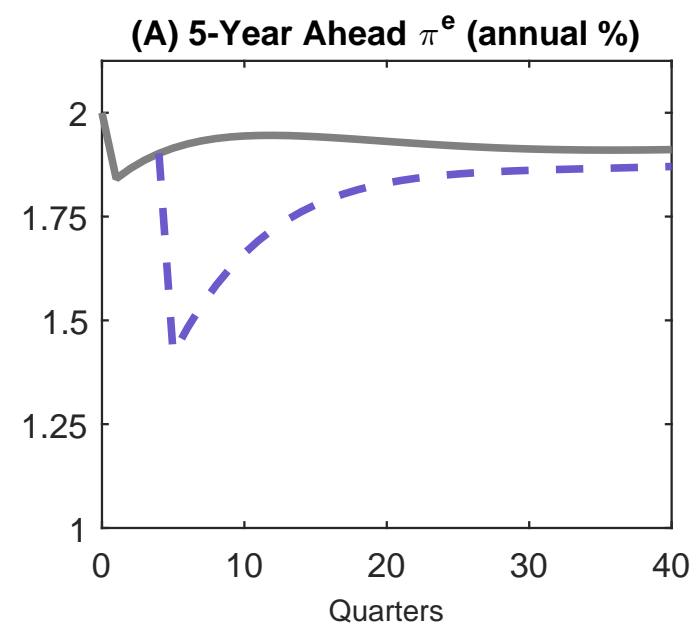

(B) Price Inflation (annual \%)

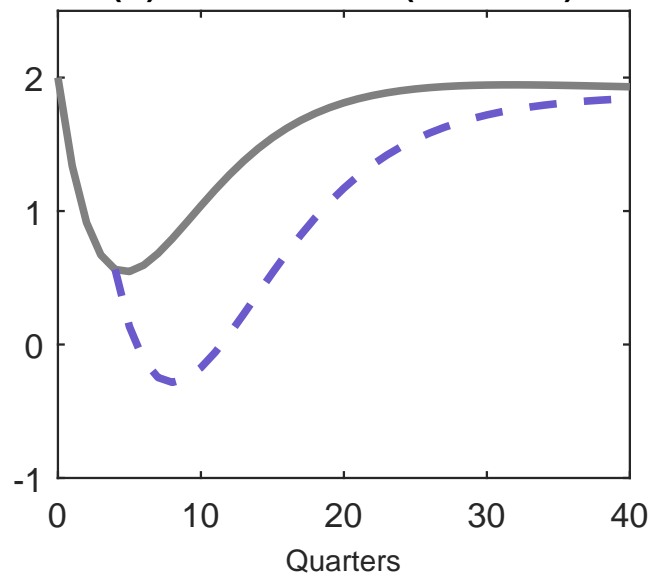

(C) Wage Inflation (annual \%)

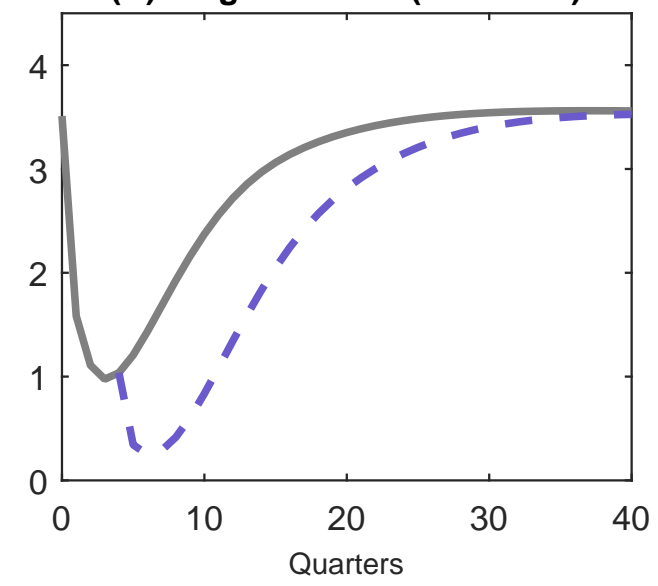

(D) Nominal Interest Rate (annual \%)

(E) Real Interest Rate (annual \%)
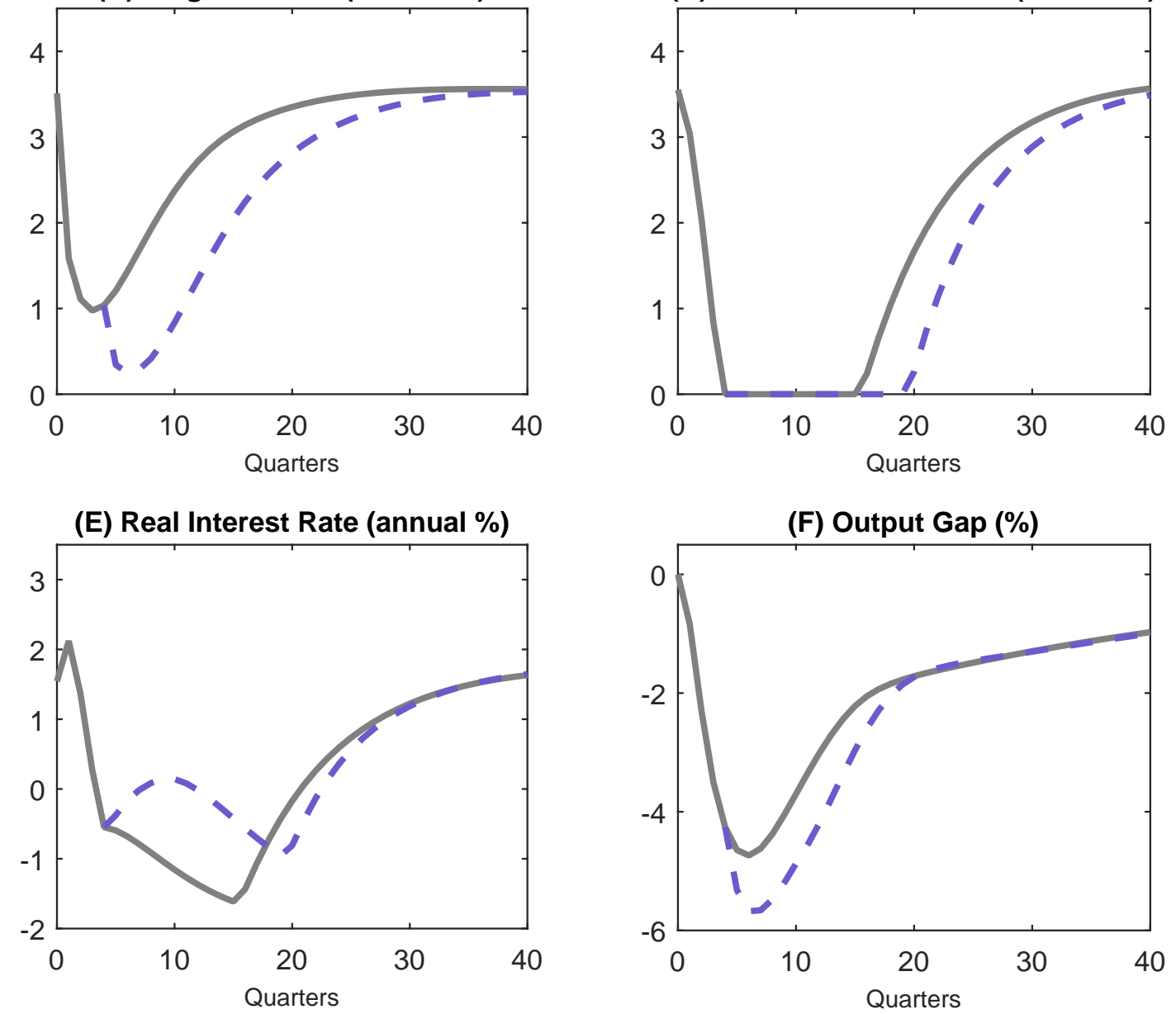

(F) Output Gap (\%)

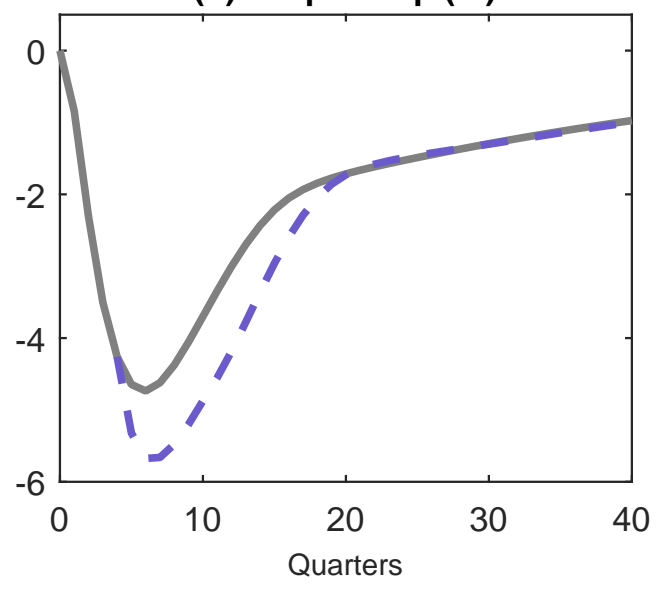

Figure 3: Effects of a decline in $\pi^{e}$ : Adaptive expectations. 
(A) Ireland

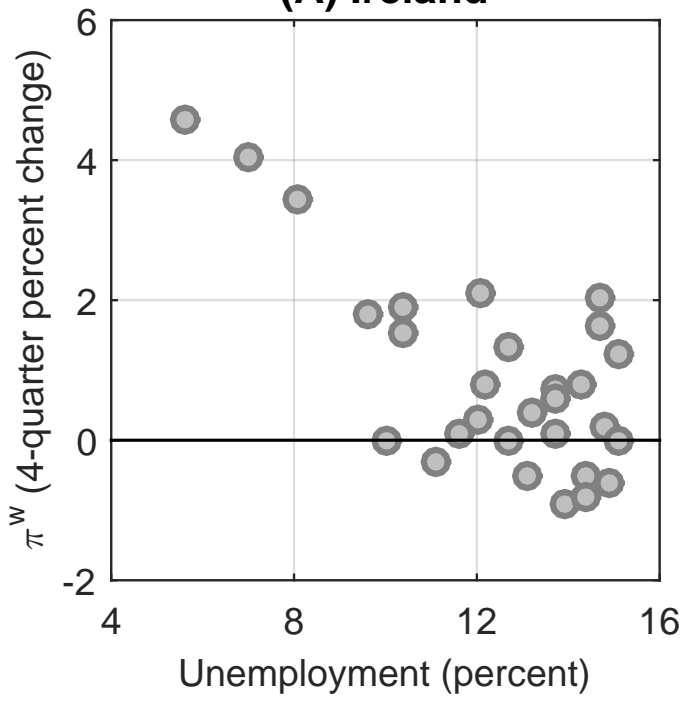

(C) Portugal

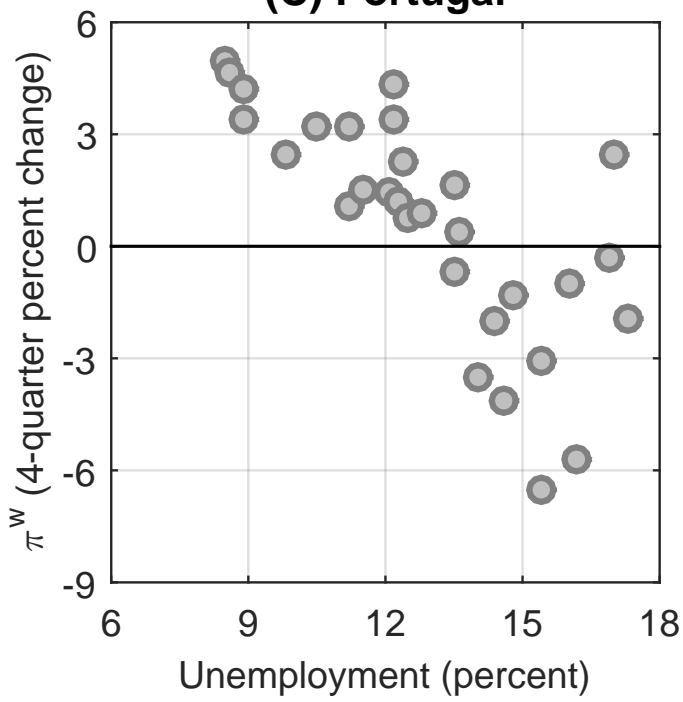

(B) Italy

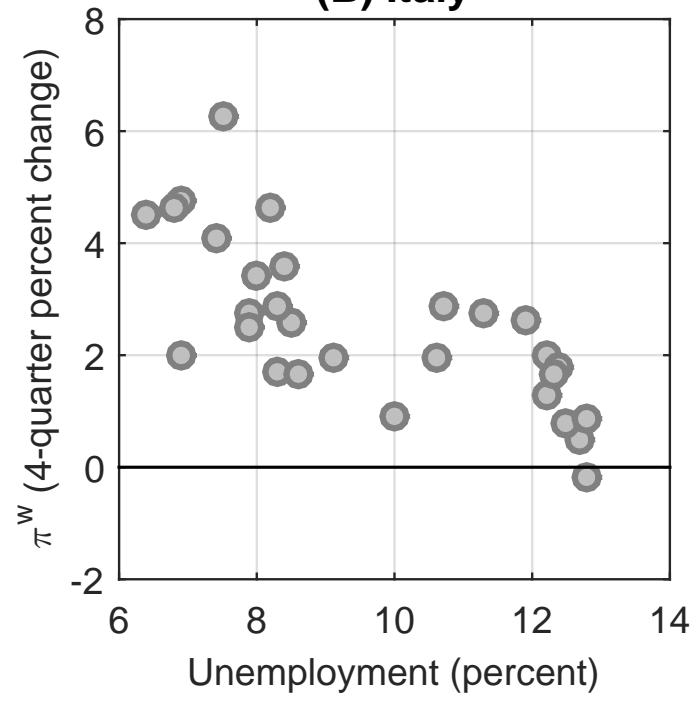

(D) Spain

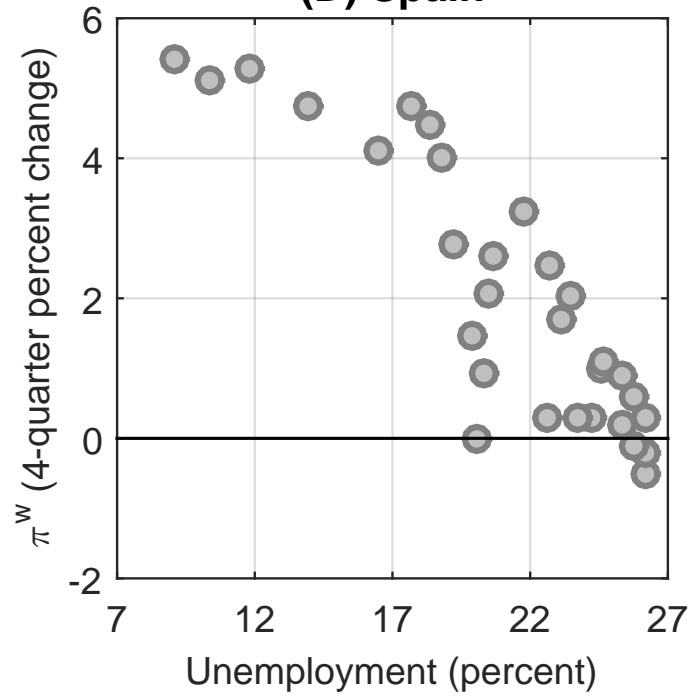

Figure 4: Wage inflation and unemployment: 2008Q1-2015Q2. 
Baseline - - More Responsive Wages

\section{(A) Wage Inflation (annual \%)}

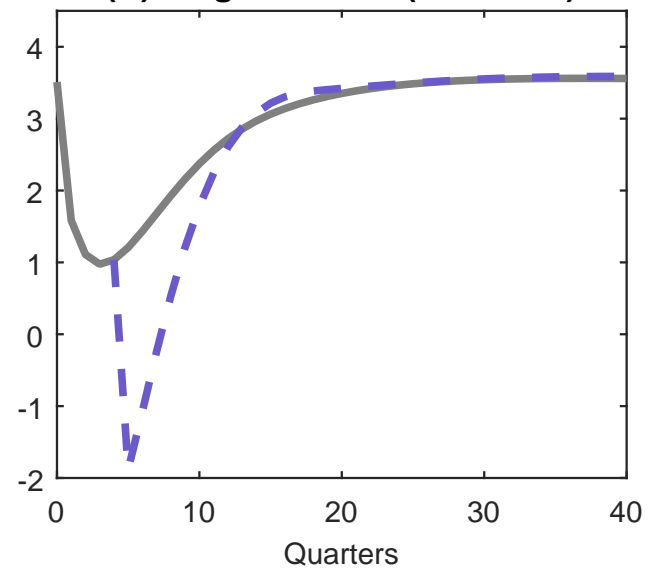

(C) Nominal Interest Rate (annual \%)

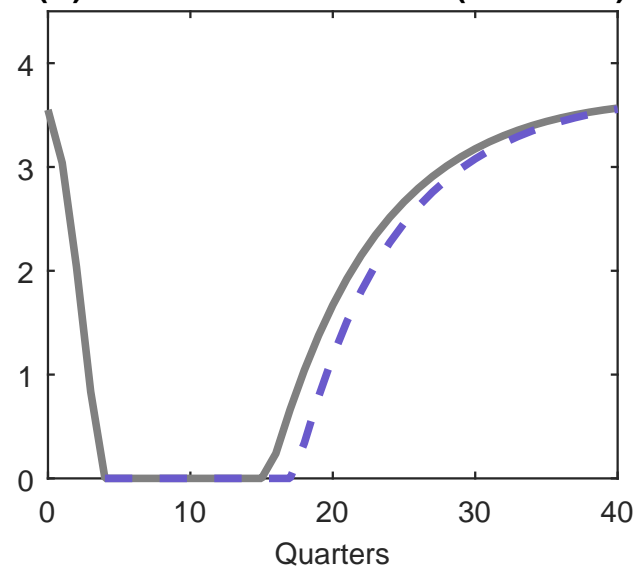

(E) Output Gap (\%)

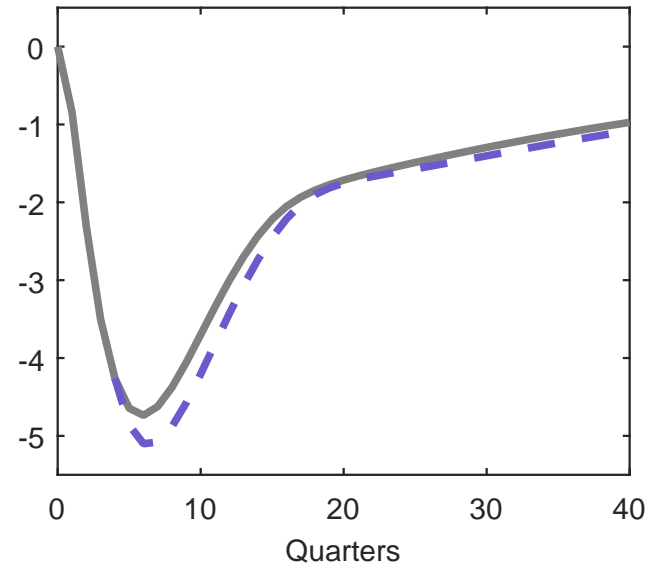

(B) Price Inflation (annual \%)

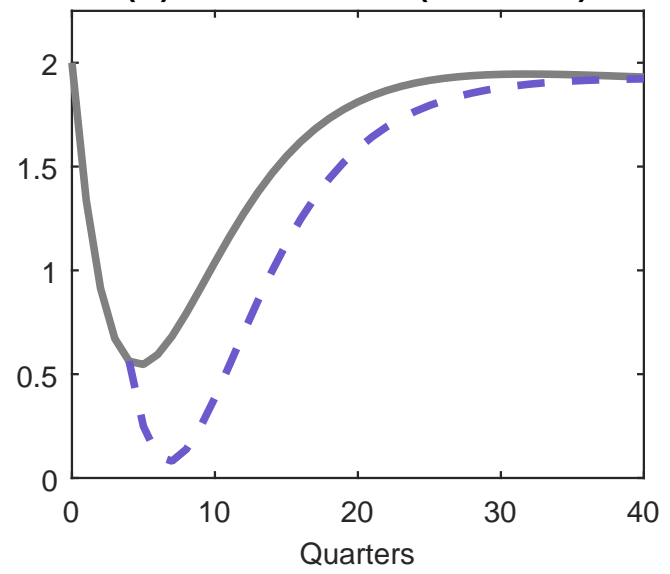

(D) Real Interest Rate (annual \%)

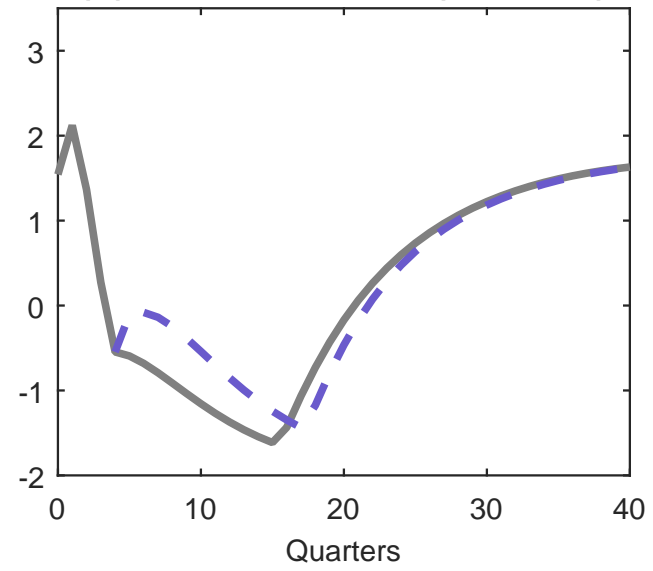

Figure 5: Effects of wages responding more to economic slack. 
_-Baseline ....... High Phillips Curve Slope - - Low Phillips Curve Slope

(A) Neutral Real Interest Rate (annual \%)

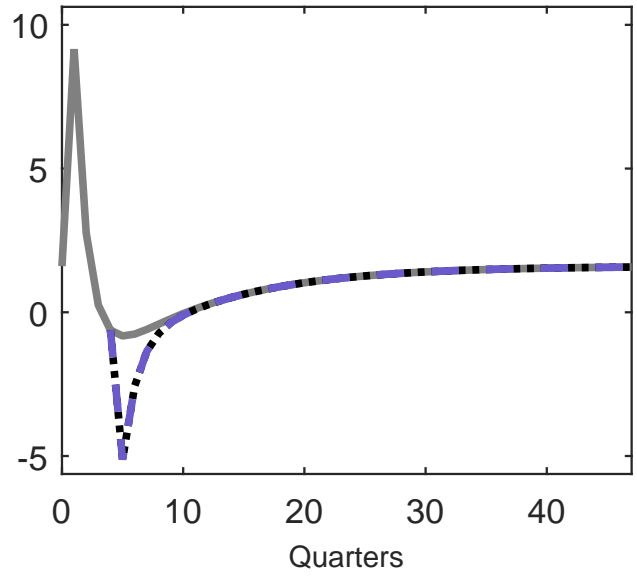

(C) Price Inflation (annual \%)

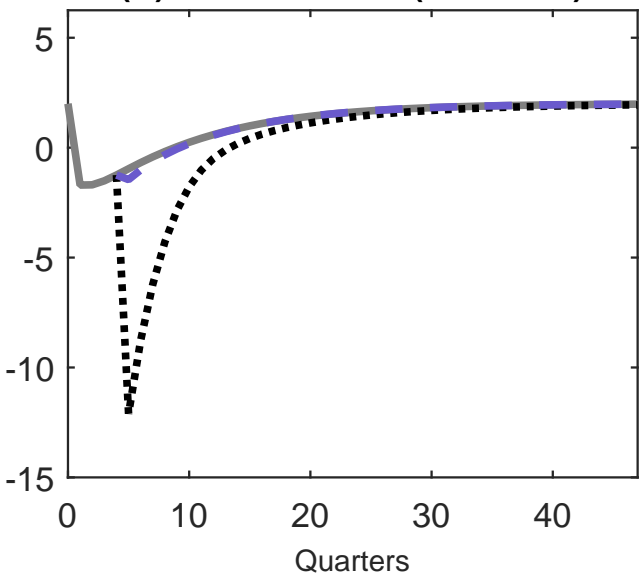

(E) Output Gap (\%)

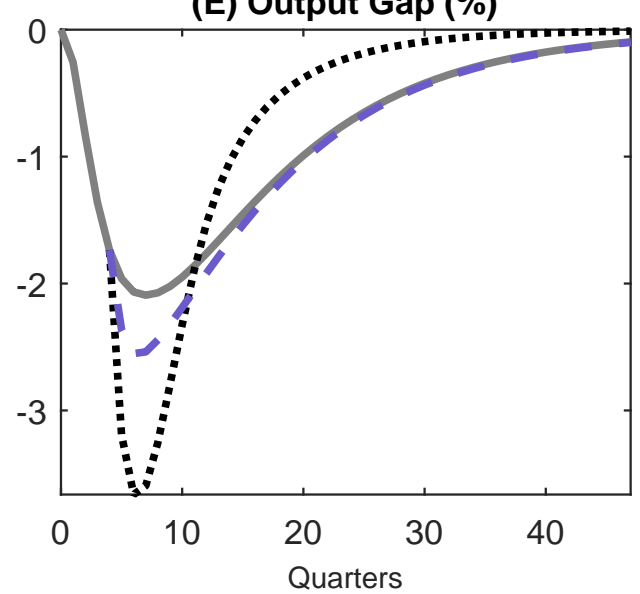

(B) Potential GDP (\% dev from ss)

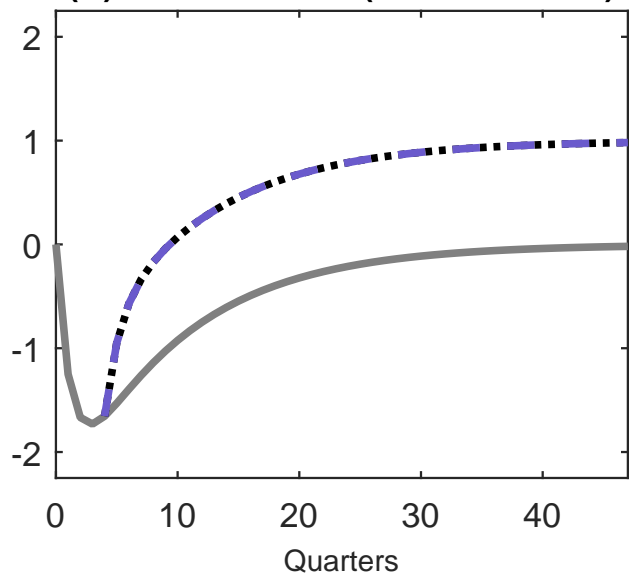

(D) Real Interest Rate (annual \%)

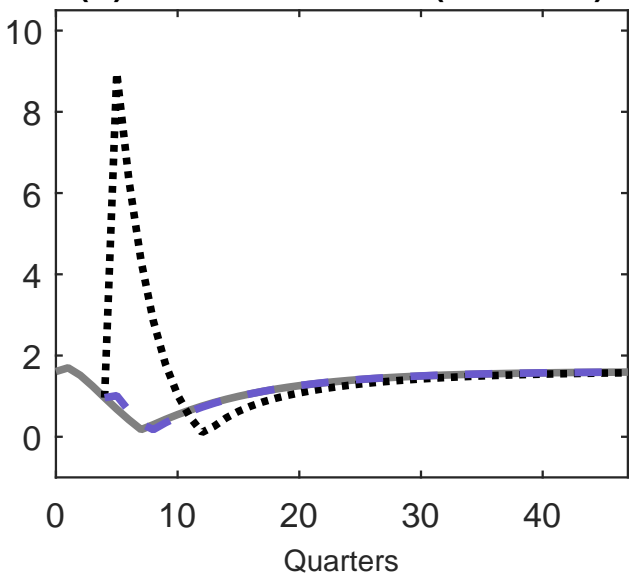

(F) GDP (\% dev from ss)

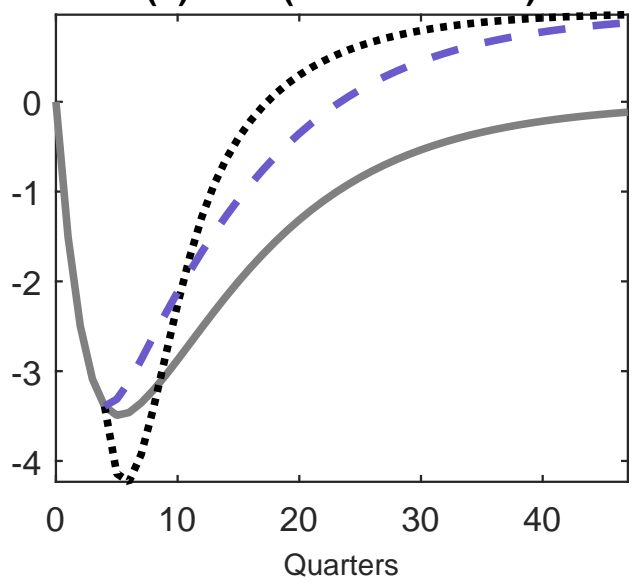

Figure 6: Effects of a rise in TFP growth: Small-scale model with flexible wages. 
Baseline - - Faster TFP Growth (i.i.d shock) '..... Faster TFP Growth (persistent shock)

(A) TFP (level \% dev from ss)

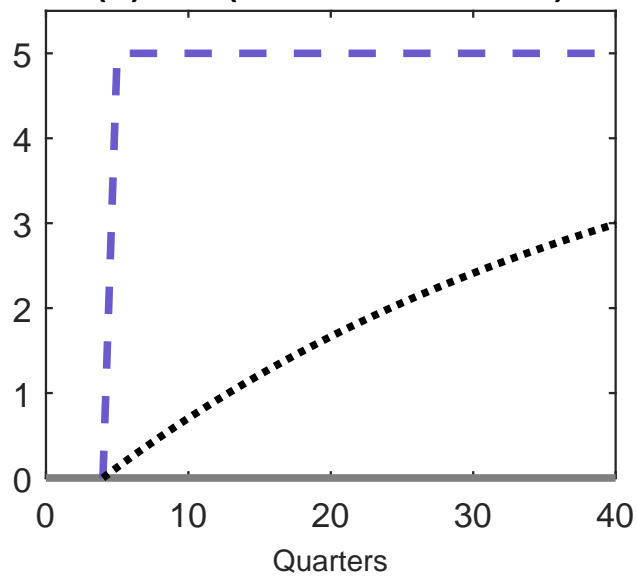

(C) Potential GDP (\% dev from ss)

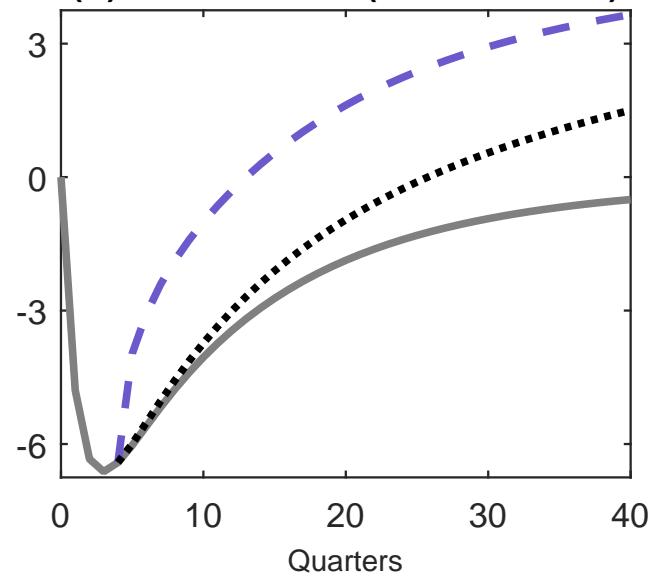

(E) Output Gap (\%)

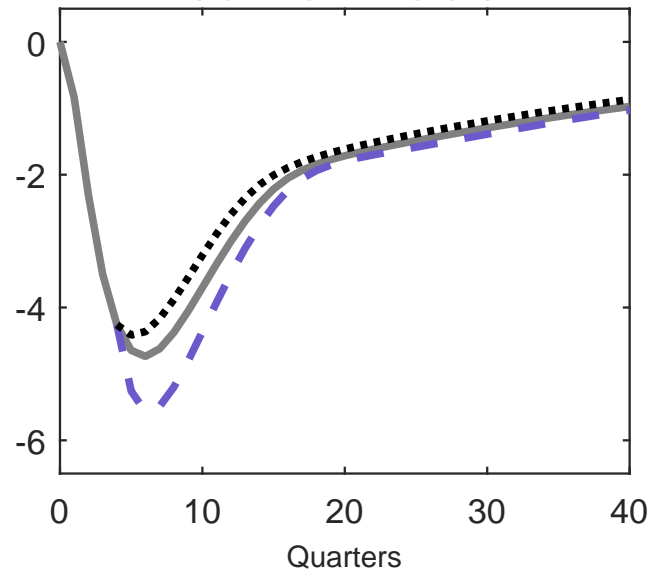

(B) Neutral Real Interest Rate (annual \%)

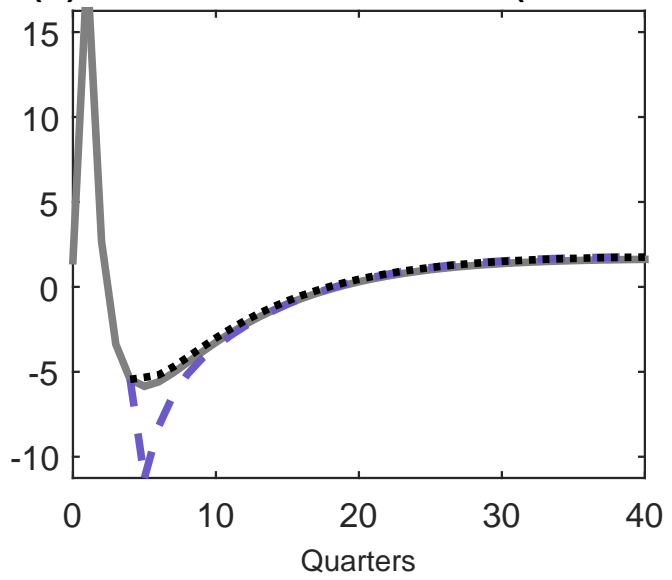

(D) Price Inflation (annual \%)

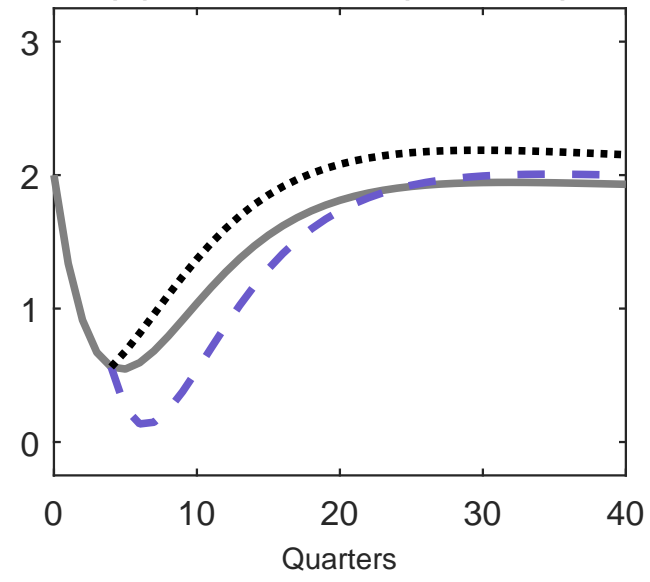

(F) GDP (\% dev from ss)

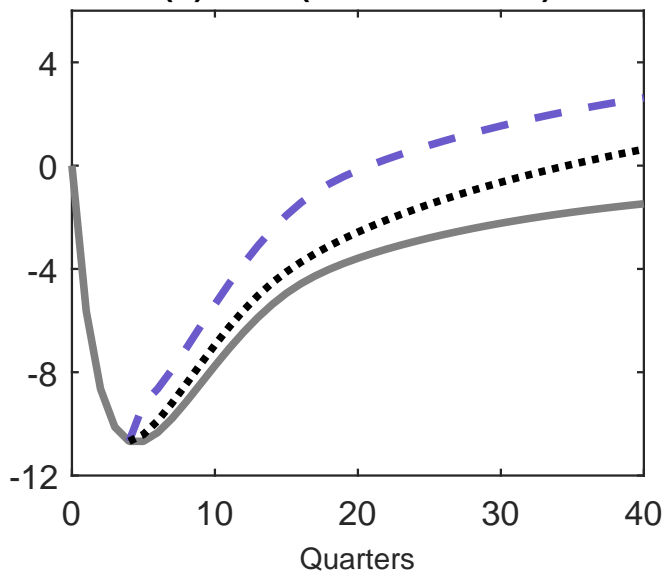

Figure 7: Effects of a rise in TFP growth. 
_Easeline - - - "True" Output Gap

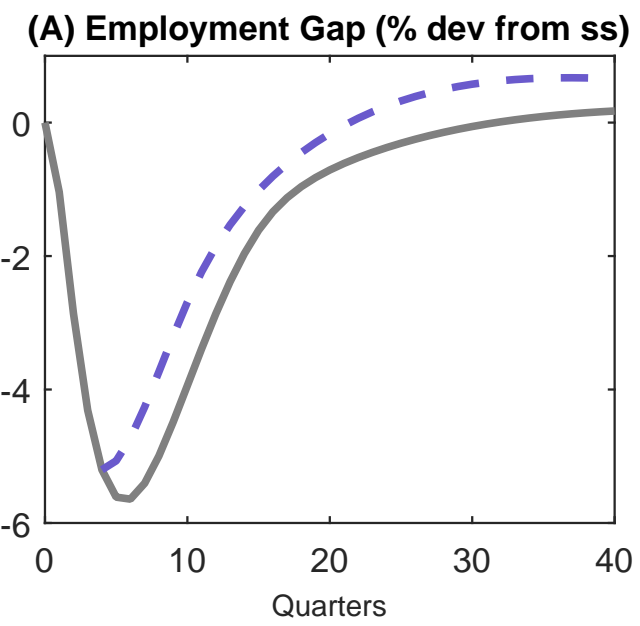

(C) Nominal Interest Rate (annual \%)

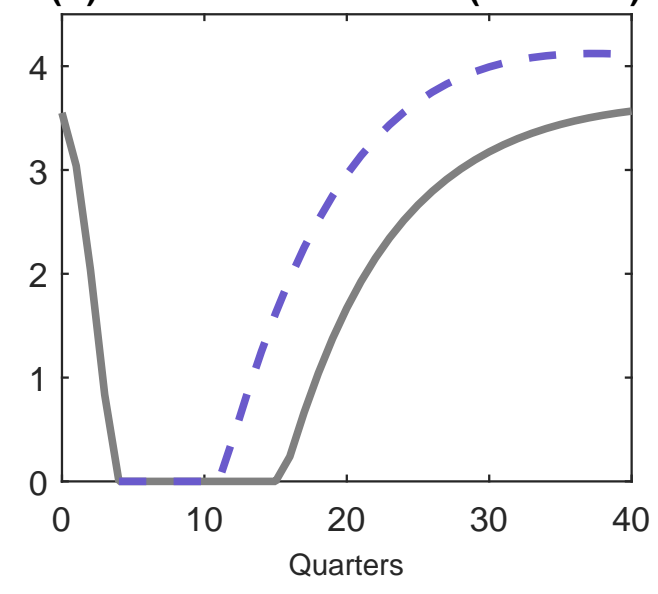

(E) Real Interest Rate (annual \%)

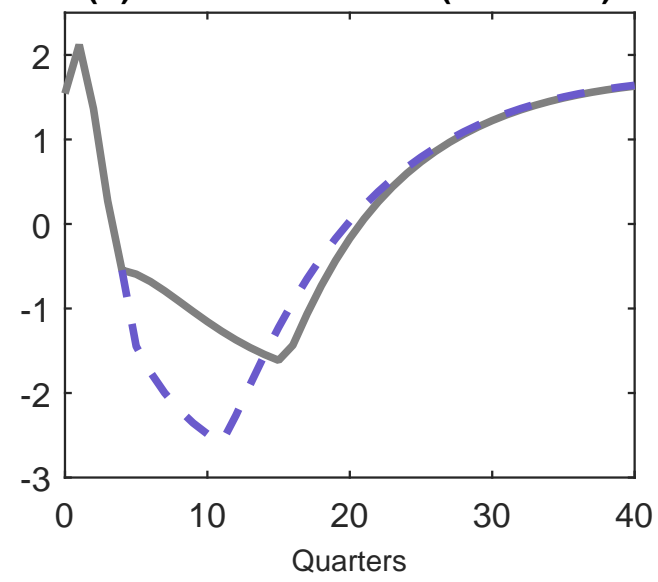

(B) Capital Gap (\% dev from ss)

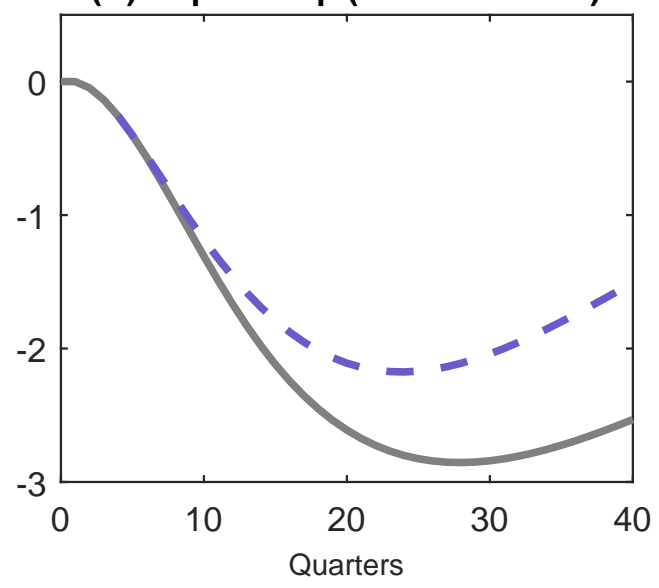

(D) Price Inflation (annual \%)

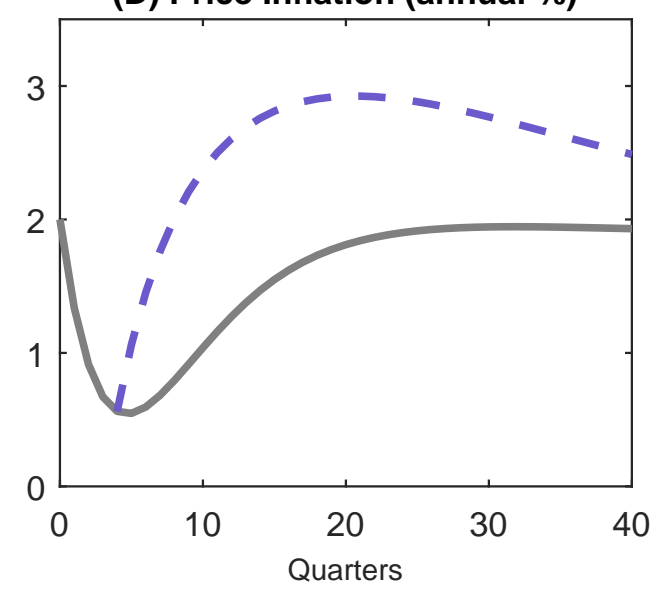

(F) Output Gap (\%)

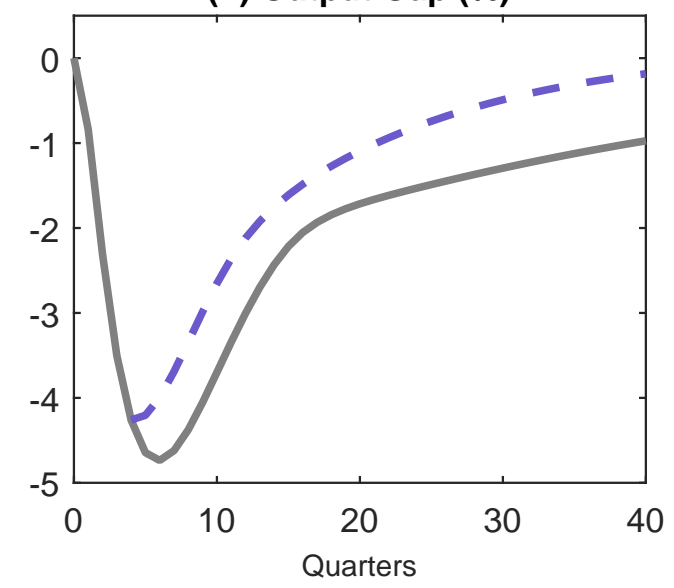

Figure 8: Effects of targeting a broad measure of resource slack. 


\section{References}

Basu, S. and B. Bundick (2015). Endogenous Volatility at the Zero Lower Bound: Implications for Stabilization Policy. NBER Working Paper No. 21838.

Blanchard, O., E. Cerutti, and L. Summers (2015). Inflation and Activity-Two Explorations and their Monetary Policy Implications. IMF Working Paper No. 15/230.

Blanchard, O. and J. Galí (2007). Real Wage Rigidities and the New Keynesian Model. Journal of Money, Credit and Banking 39(S1), 35-65.

Brave, S. A., J. R. Campbell, J. D. Fisher, and A. Justiniano (2012). The Chicago Fed DSGE Model. Federal Reserve Bank of Chicago Working Paper, WP 2012-02.

Calvo, G. A. (1983). Staggered Prices in a Utility-Maximizing Framework. Journal of Monetary Economics 12(3), 383-398.

Christiano, L. J., M. Eichenbaum, and C. L. Evans (2005). Nominal Rigidities and the Dynamic Effects of a Shock to Monetary Policy. Journal of Political Economy 113(1), $1-45$.

Christiano, L. J., M. S. Eichenbaum, and M. Trabandt (2015). Understanding the Great Recession. American Economic Journal: Macroeconomics 7(1), 110-167.

Clarida, R., J. Gali, and M. Gertler (1999). The Science of Monetary Policy: A New Keynesian Perspective. Journal of Economic Literature 37(4), 1661-1707.

Constâncio, V. (2014). Recent Challenges to Monetary Policy in the Euro Area. Speech 
by Vitor Constâncio, Vice-President of the ECB, at the Athens Symposium on Banking Union, Monetary Policy and Economic Growth, Athens, 19 June 2014.

De Michelis, A. and M. Iacoviello (2016). Raising an Inflation Target: the Japanese Experience with Abenomics. European Economic Review (Forthcoming).

Domeij, D. and M. Floden (2006). The Labor-Supply Elasticity and Borrowing Constraints: Why Estimates are Biased. Review of Economic Dynamics 9(2), 242-262.

Draghi, M. (2014). Unemployment in the Euro Area. Speech by Mario Draghi, President of the ECB, Annual Central Bank Symposium in Jackson Hole, 22 August 2014.

Eggertsson, G., A. Ferrero, and A. Raffo (2014). Can Structural Reforms Help Europe? Journal of Monetary Economics 61, 2-22.

Eggertsson, G. B. (2010). The Paradox of Toil. FRB of New York Staff Report (433).

Eggertsson, G. B. and P. Krugman (2012). Debt, Deleveraging, and the Liquidity Trap: A Fisher-Minsky-Koo Approach*. The Quarterly Journal of Economics 127(3), 1469-1513.

Eggertsson, G. B. and M. Woodford (2003). The Zero Bound on Interest Rates and Optimal Monetary Policy. Brookings Papers on Economic Activity 1, 139-232.

Erceg, C. J., D. W. Henderson, and A. T. Levin (2000). Optimal Monetary Policy with Staggered Wage and Price Contracts. Journal of Monetary Economics 46(2), 281-313.

Erceg, C. J. and A. T. Levin (2014). Labor Force Participation and Monetary Policy in the Wake of the Great Recession. Journal of Money, Credit and Banking 46(S2), 3-49. 
Fernández-Villaverde, J. (2014). Discussion of "Can Structural Reforms Help Europe?" by Gauti Eggertsson, Andrea Ferrero, and Andrea Raffo. Journal of Monetary Economics.

Fernández-Villaverde, J., P. Guerrón-Quintana, and J. F. Rubio-Ramírez (2014). Supply-side Policies and the Zero Lower Bound. IMF Economic Review 62(2), 248-260.

Hills, T., T. Nakata, and S. Schmidt (2016). The Risky Steady State and the Interest Rate Lower Bound. FEDS Working Paper 2016-009.

Kuroda, S. and I. Yamamoto (2005). Wage Fluctuations in Japan After the Bursting of the Bubble Economy: Downward Nominal Wage Rigidity, Payroll, and the Unemployment Rate. Institute for Monetary and Economic Studies, Bank of Japan.

Orphanides, A. (2003). The Quest for Prosperity without Inflation. Journal of Monetary Economics 50(3), 633-663.

Smets, F. and R. Wouters (2003). An Estimated Dynamic Stochastic General Equilibrium Model of the Euro Area. Journal of the European Economic Association 1(5), 1123-1175.

Smets, F. and R. Wouters (2007). Shocks and Frictions in U.S. Business Cycles: A Bayesian DSGE Approach. The American Economic Review 97(3), 586-606.

Svensson, L. (2013). Some Lessons from Six Years of Practical Inflation Targeting. Mimeo.

Viner, J. (1933). Balanced Deflation, Inflation, or More Depression. The University of Minnesota Press.

Wieland, J. (2015). Are Negative Supply Shocks Expansionary at the Zero Lower Bound. Mimeo. 
Woodford, M. (2003). Interest and Prices: Foundations of a Theory of Monetary Policy. Princeton University Press. Princeton, New Jersey.

Yun, T. (1996). Nominal Price Rigidity, Money Supply Endogeneity, and Business Cycles. Journal of Monetary Economics 37(2), 345-370. 